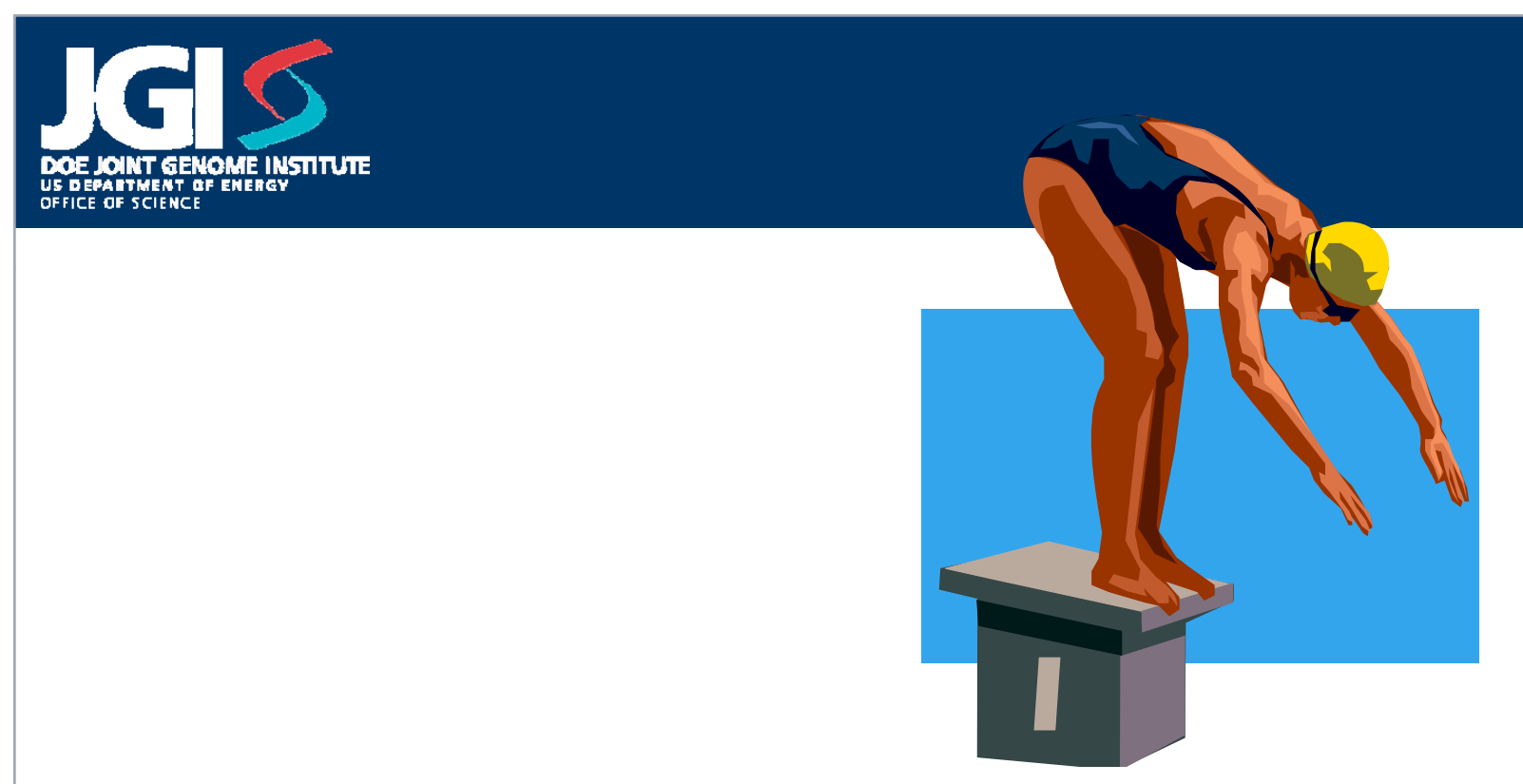

\title{
Ready, set...go!
}

\section{Presented at the}

\section{COEH Summer Institute}

\section{By Melanie Alexandre, MS, OTR, CPE}

The work conducted by the U.S. Department of Energy Joint Genome Institute is supported by the Office of Science of the U.S. Department of Energy under Contract No. DE-AC02-05CH11231 


\section{Objectives}

- Discuss organizational readiness for changes in an ergonomics program or intervention

- Assessing organizational readiness

- Benefits and challenges of change

- Case studies of ergonomic programs that were 'not ready' and 'ready' 


\section{LIS Let's see if we are ready...

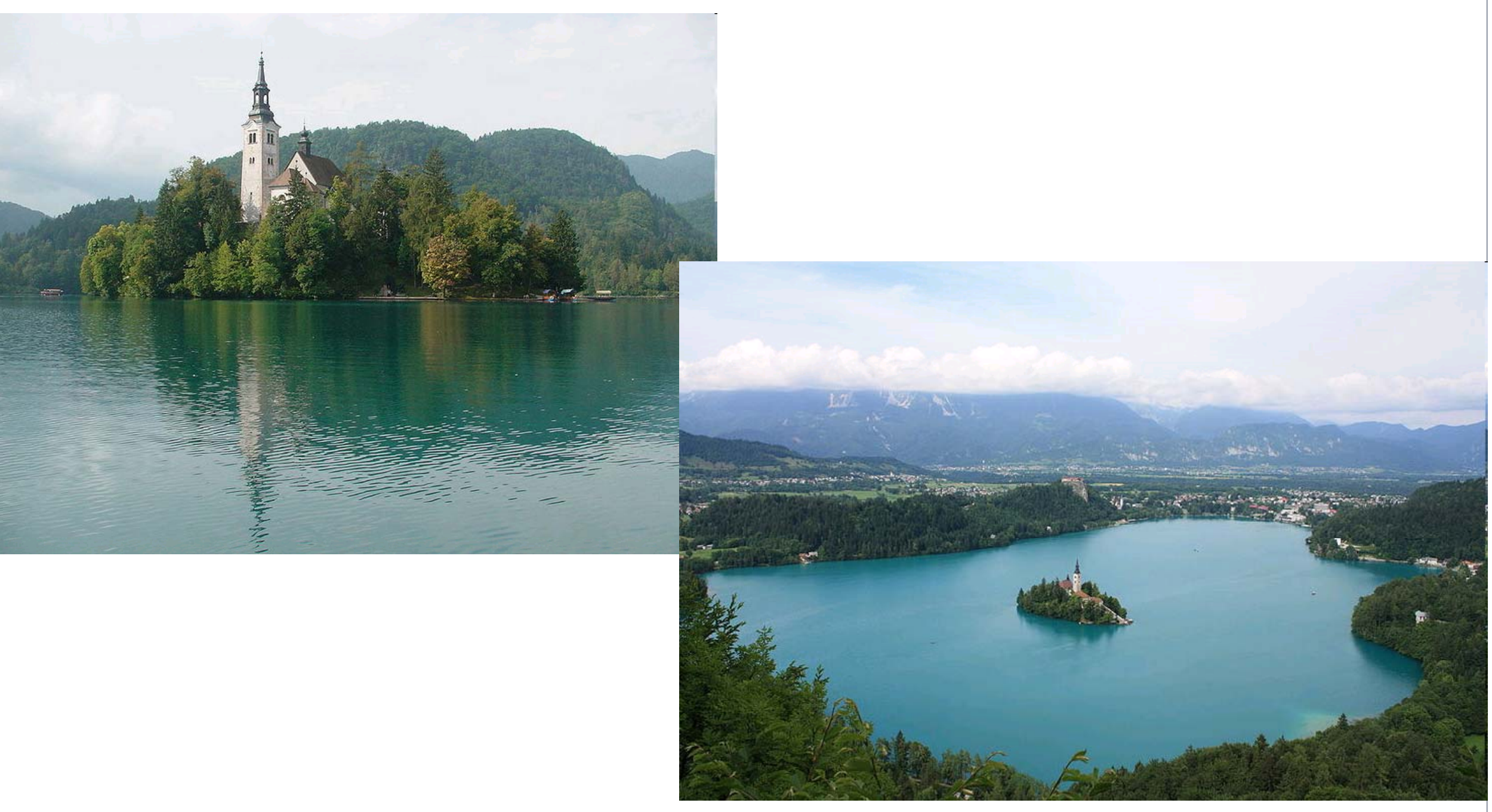




\section{Break into groups}

- Objective:

- Everyone in your group must get from the island to the shore

- Determine what you need to know to decide if you are 'ready' to perform this task

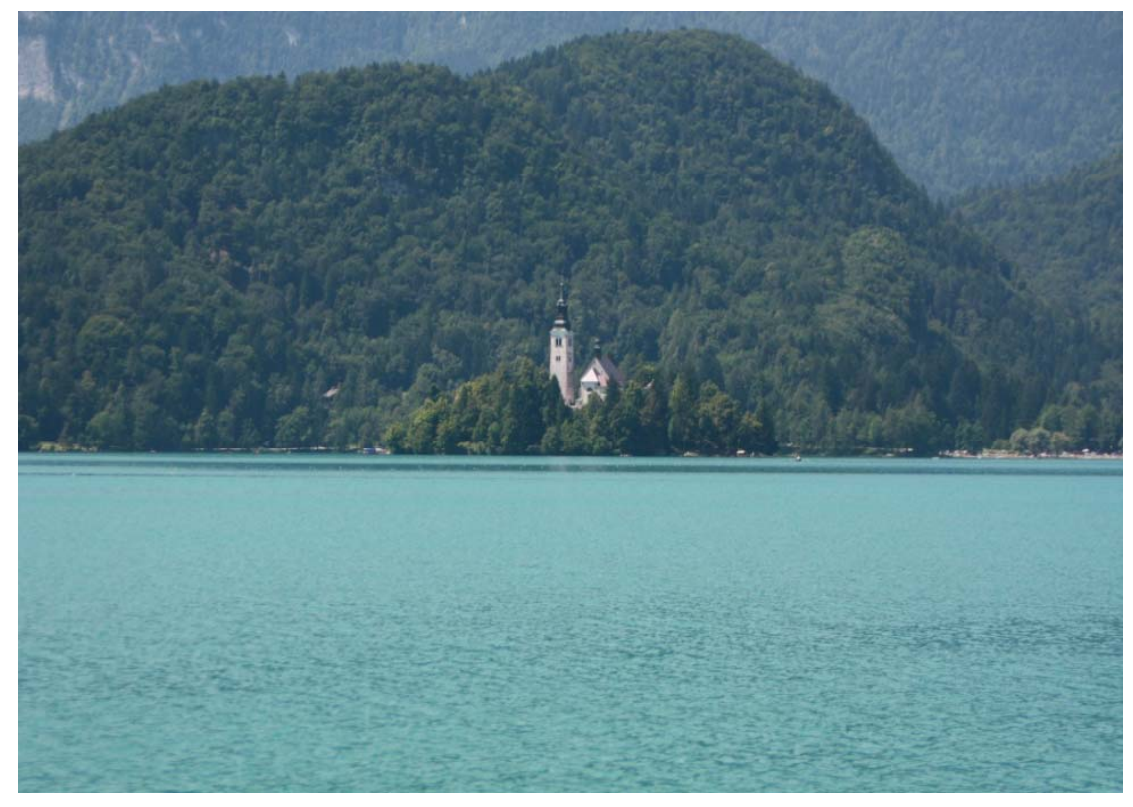


What were some of your 'readiness' questions?

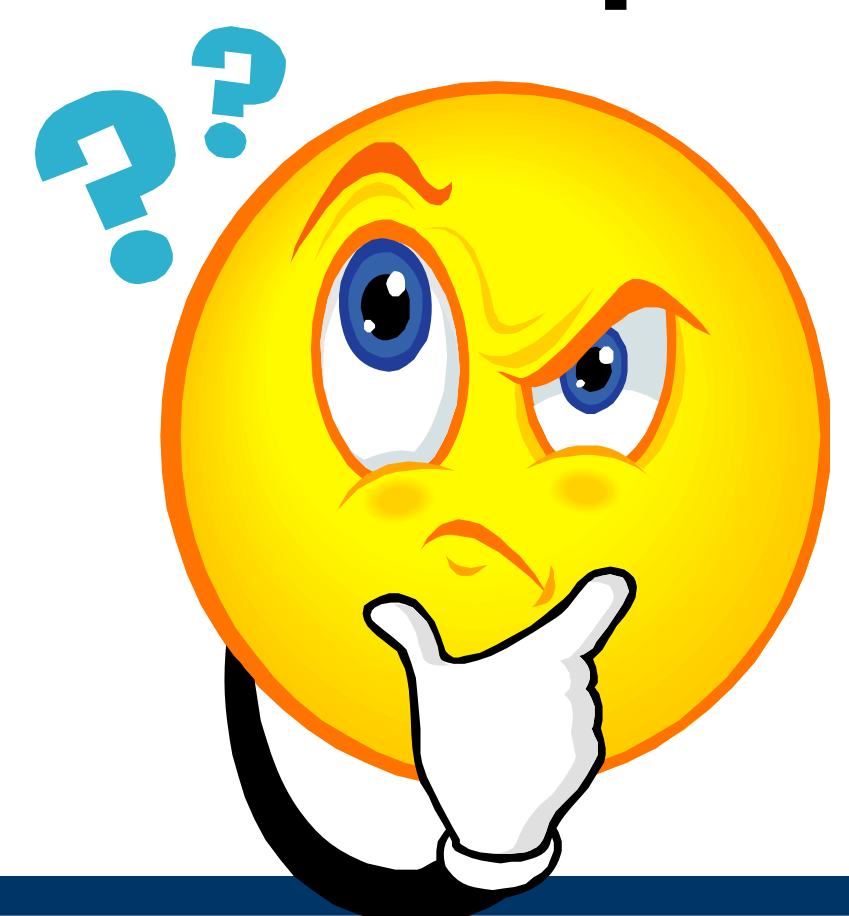




\section{JCISAssessing organizational readiness

- Why did they contact you?

- How motivated are the management and employees to change?

- Who are the 'champions' and 'leaders' on the team?

- Are there clear goals, objectives, and ways to

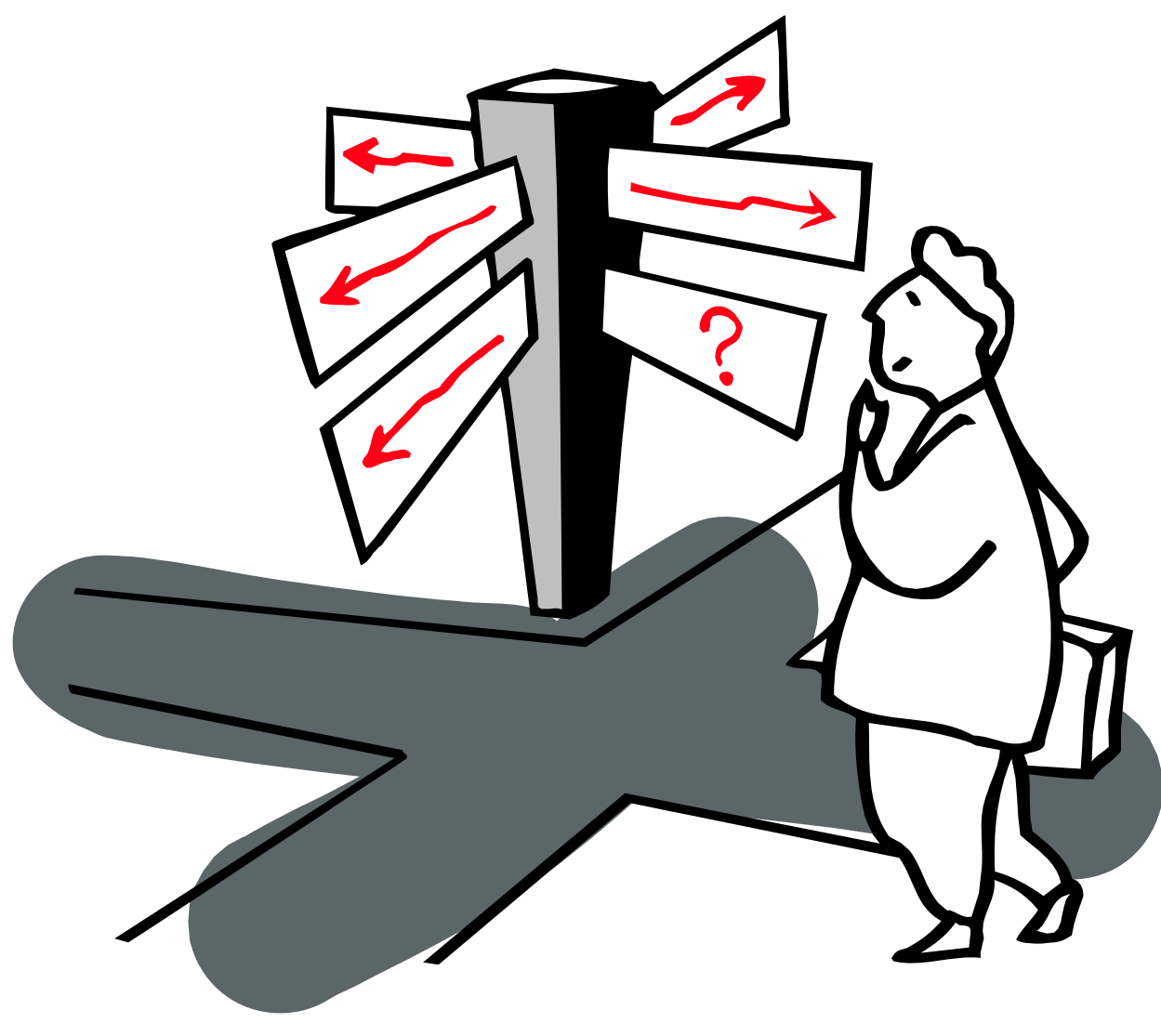
measure success? 


\section{Assessing organizational
readiness (continued)}

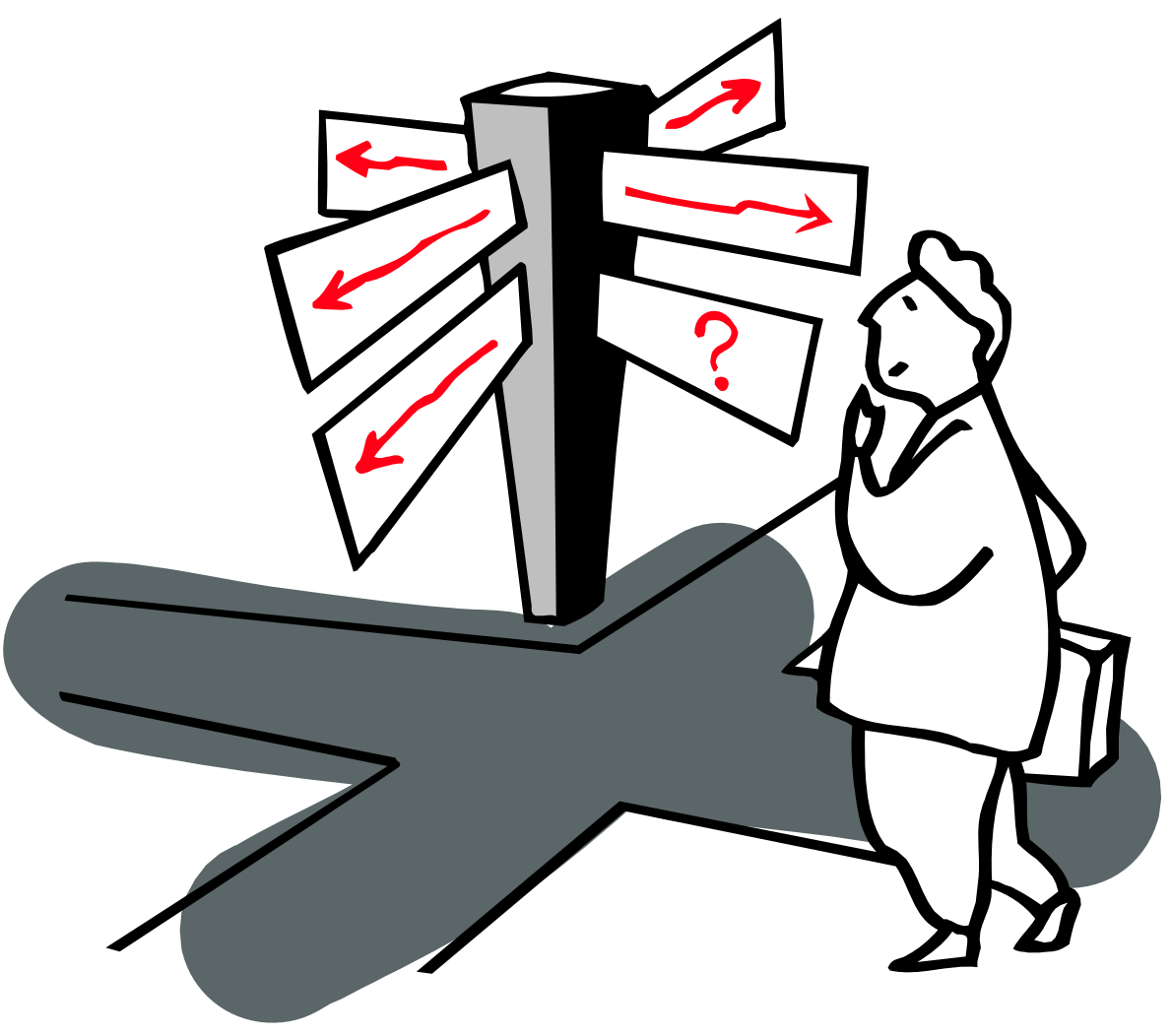

- Is the 'climate' right?

- Can everyone 'swim'?

- Is everyone on board?

- What obstacles are in the way?

- Are there mechanisms in place that will allow the efforts to be sustainable? 


\section{Benefits of change}

- Changes in ergonomics program or intervention can lead to:

- Improved efficiencies

- Improved productivity

- Reduction in cycle time

- Cost savings

- Reduction in ergonomics risks or injuries

- Employee satisfaction

- Fostering a culture that promotes/ embraces change
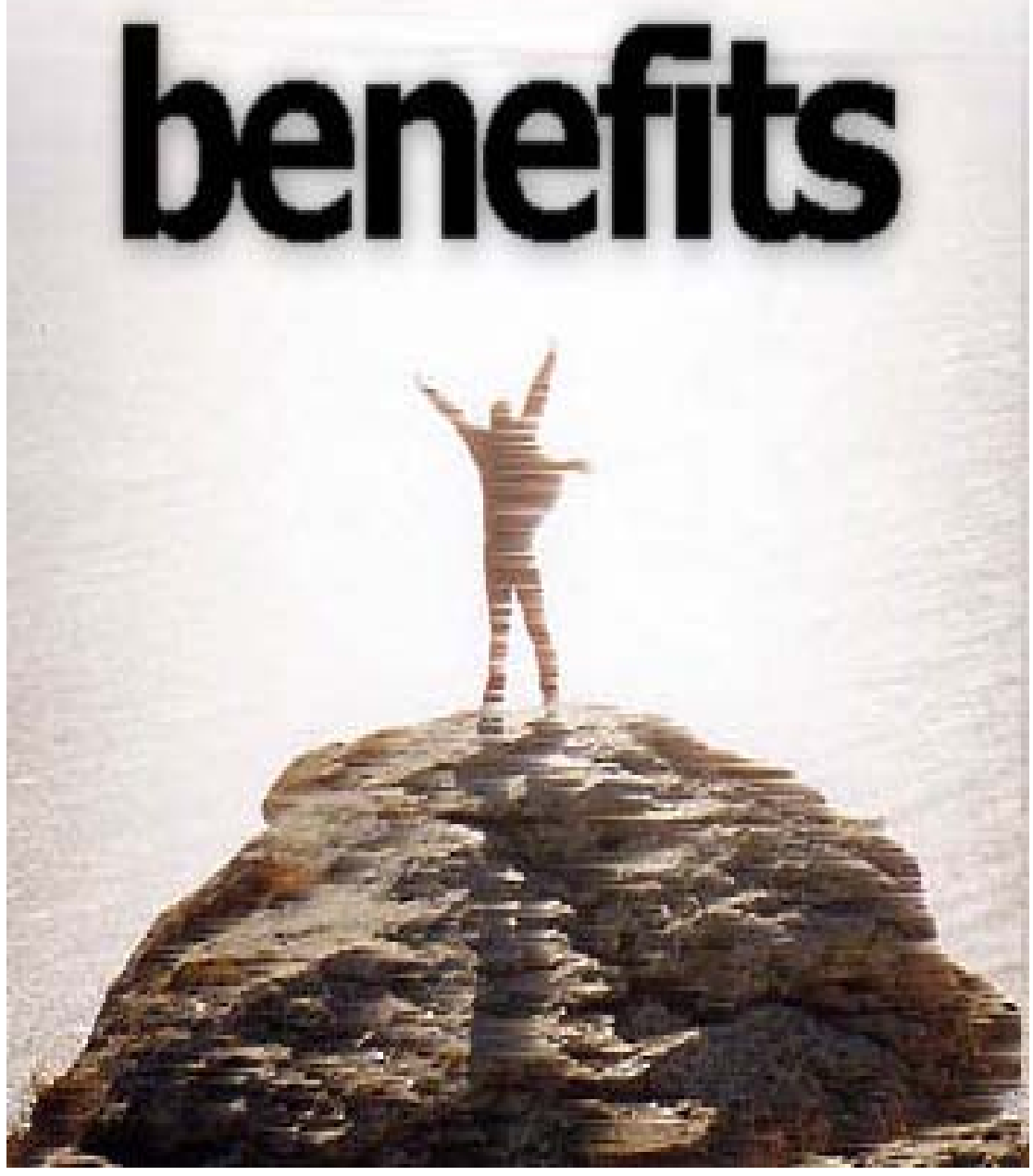


\section{Challenges of change}

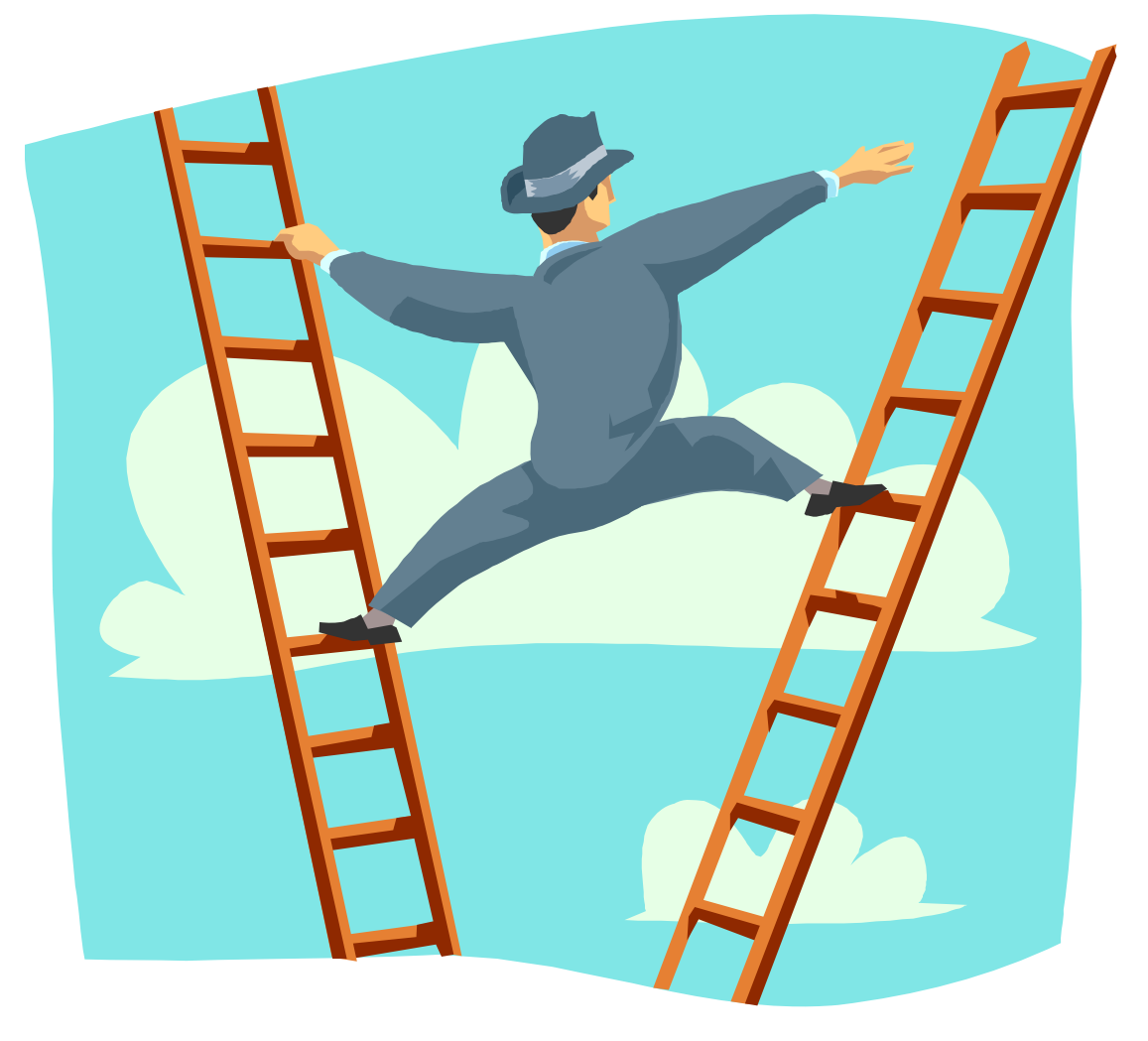

- Changes in ergonomics program or intervention can be challenging because:

- Fear of:

- Unknown

- Failure

- Potential risks

- May disagree about the need for change and best course of action

- Lack of trust

- Costs may exceed gains

- May not understand 'why'

- Requires effort

- Lack of participation, leadership, or clear objectives/ goals 


Case study of ergonomics program
that was ' not ready'

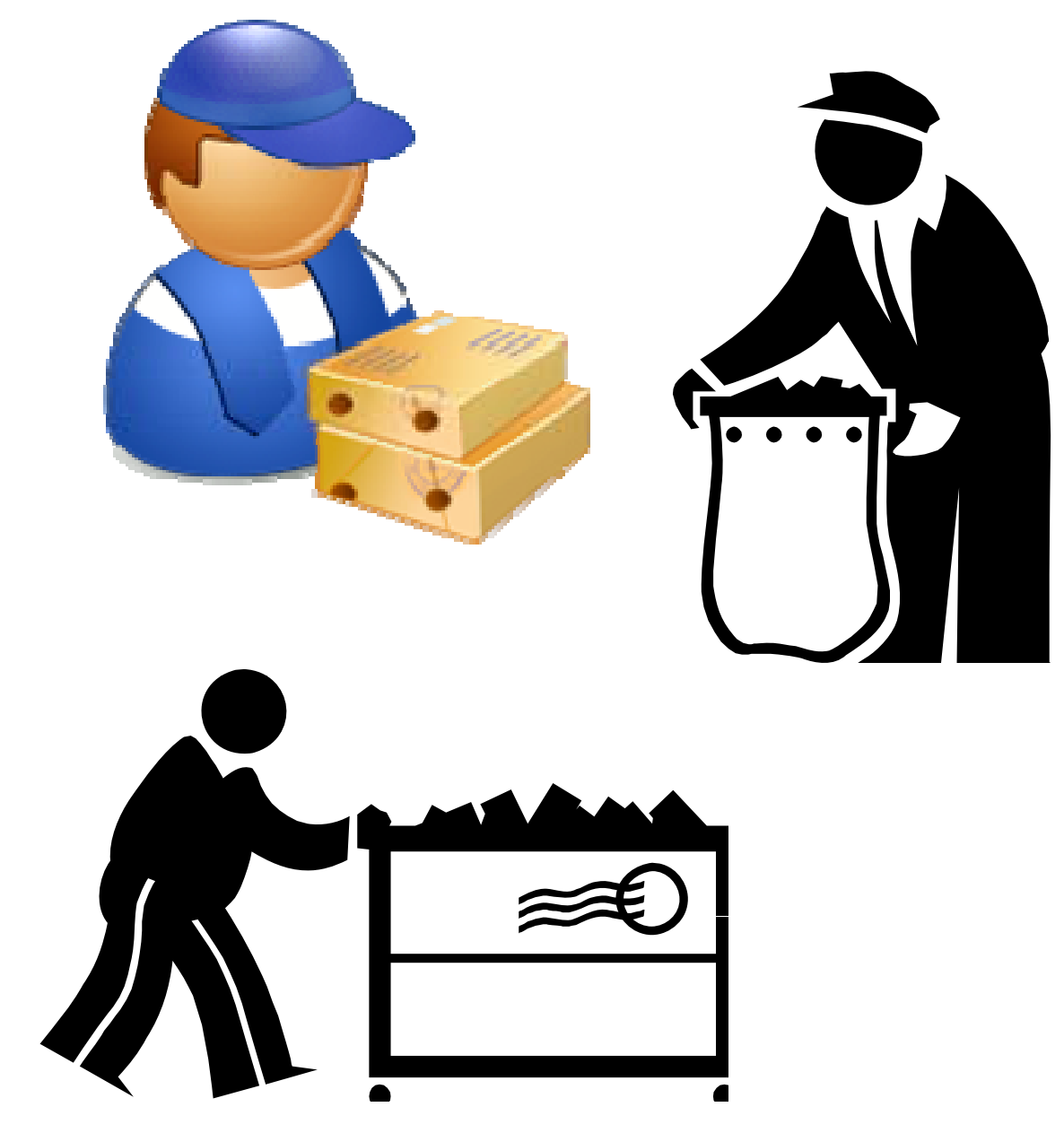

- Help requested by an employee in a mail distribution center to come identify risks and solutions

- Supervisor was supportive

- Management was not! 


\section{JC Case study of ergonomics program that was 'ready'}

DOE Joint Genome Institute-Production Genomics Facility

The Human Genome 2003

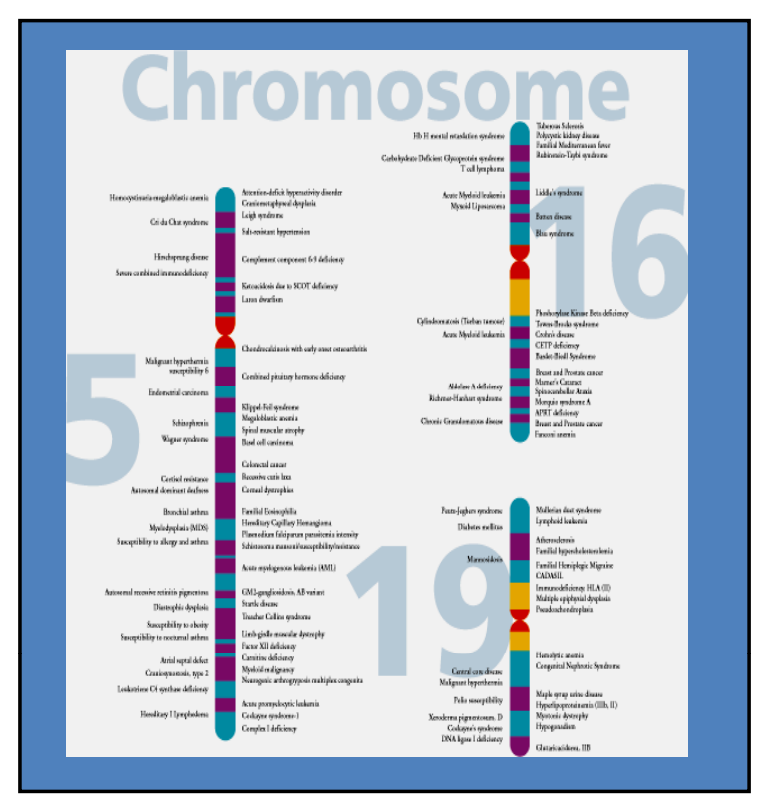

Current DOE Mission Relevance

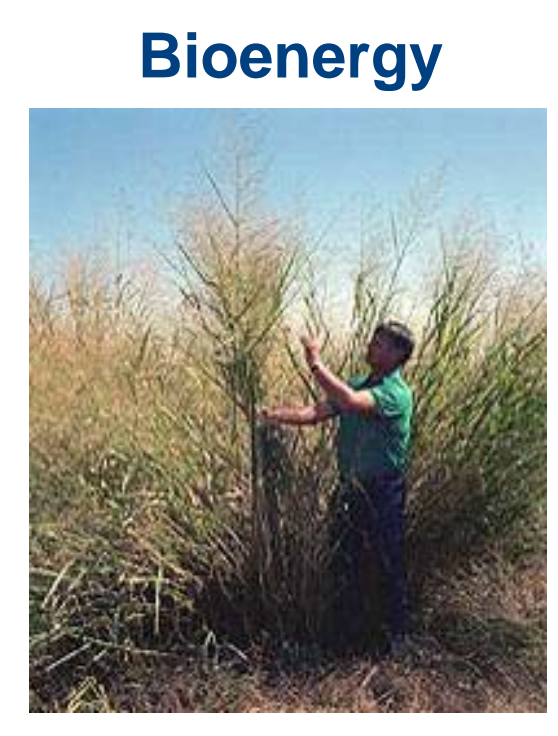

\section{Biogeochemistry}

Carbon Cycling
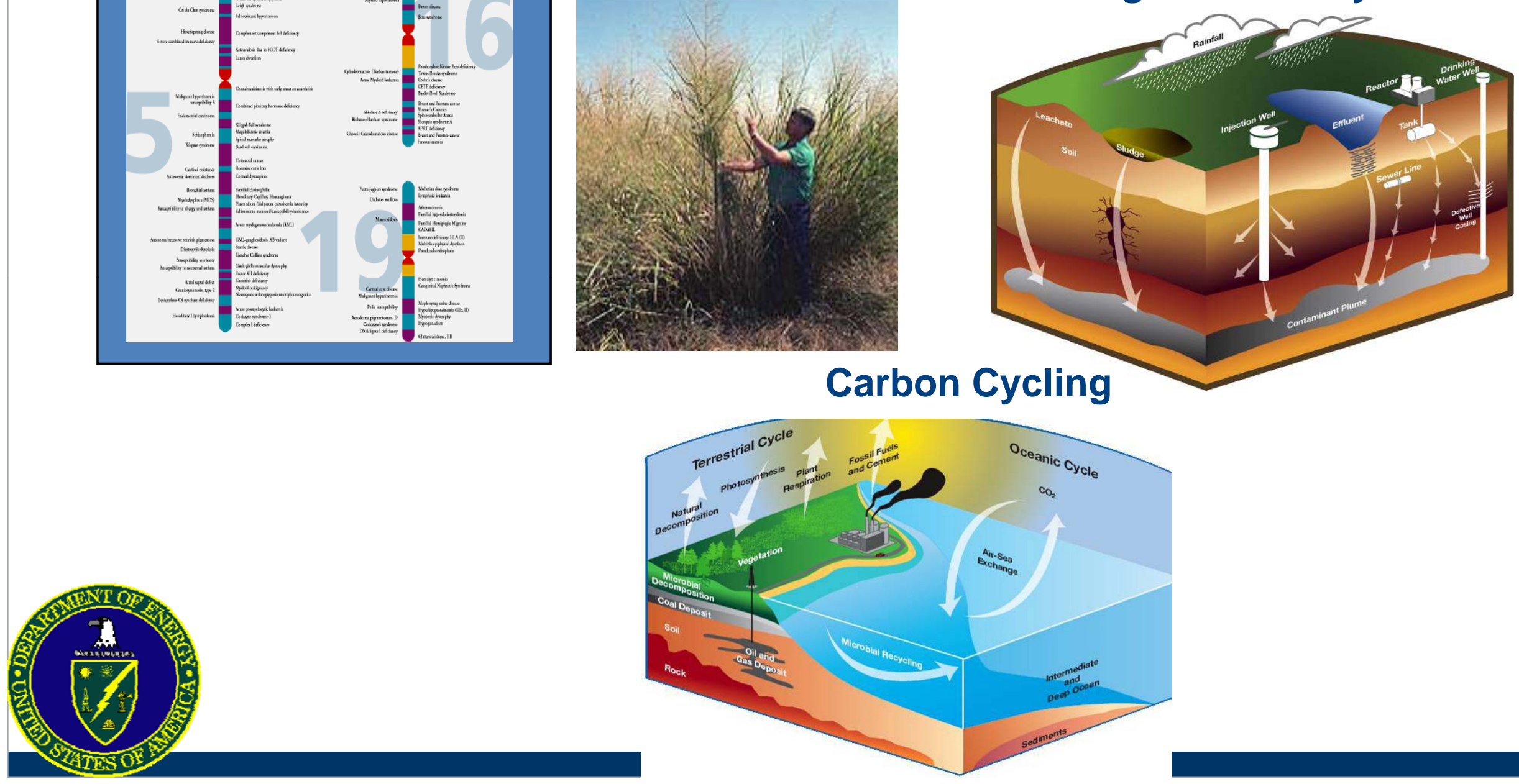


\section{JCIS Office \& Manufacturing Work Environments}

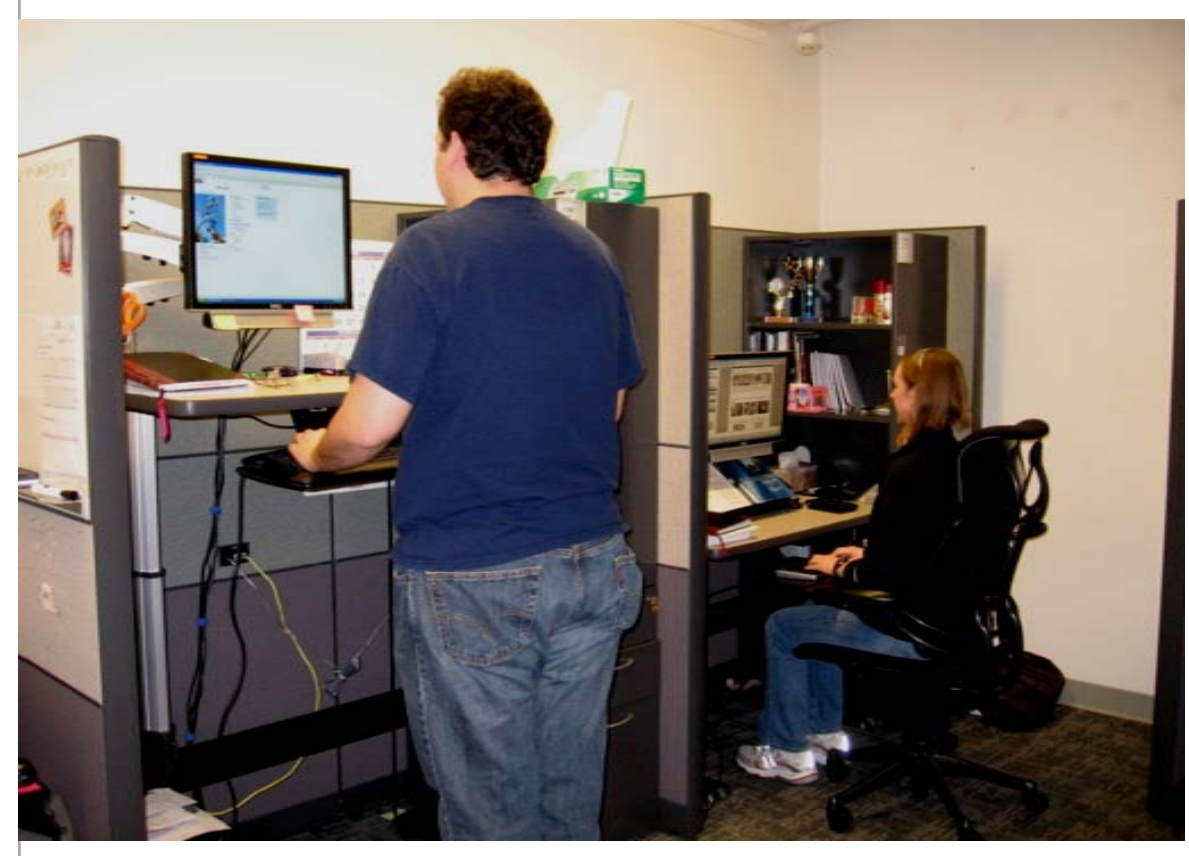

$60 \%$ staff in computerintensive office settings

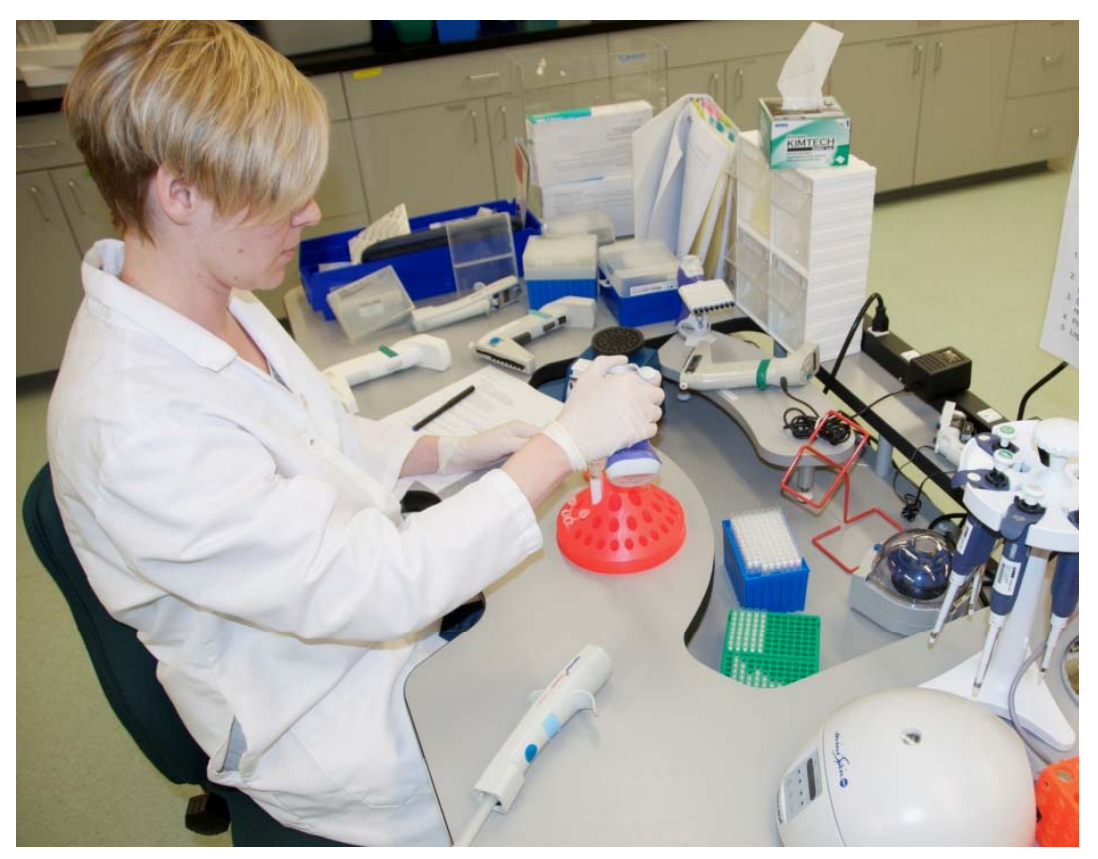

$40 \%$ staff in handintensive production tasks

(2 shifts) 


\section{Root Causes of Ergonomic Injuries}

- Equipment/instruments designed for small batches used for high throughput operation

- Culture:

- Understanding Efficiency vs. Speed

- High force handintensive tasks

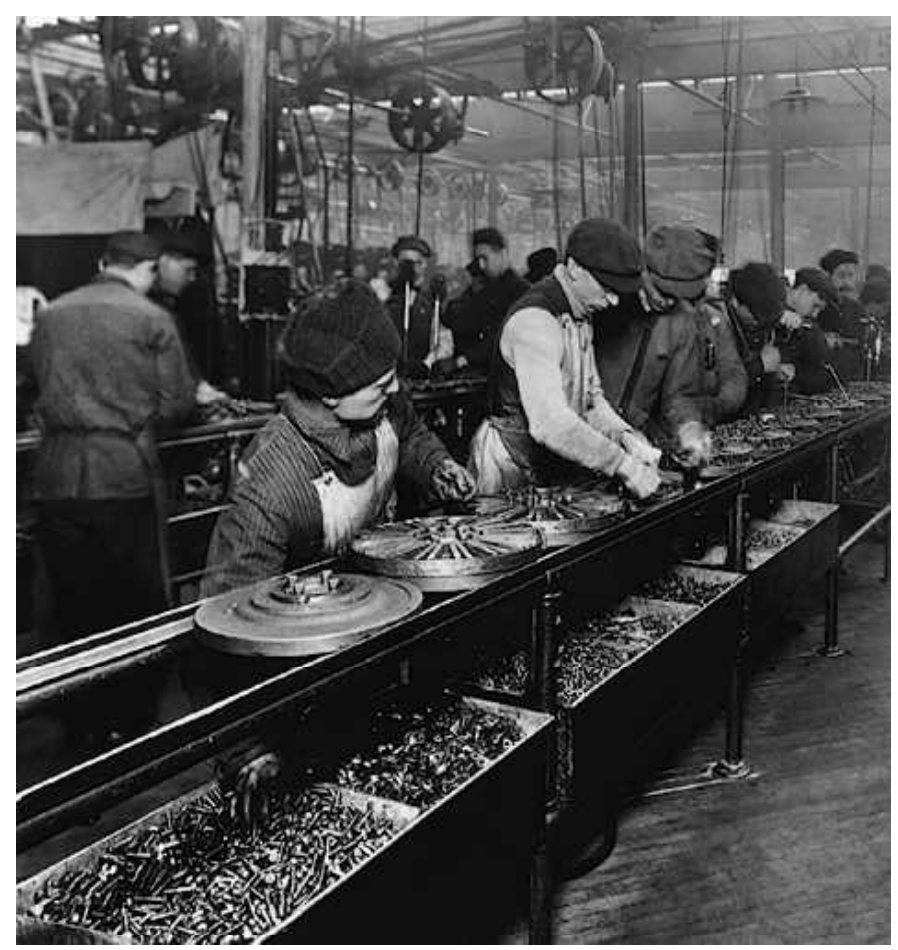

We are striving to determine how much is too much 


\section{JIs Was this easy... no way!}
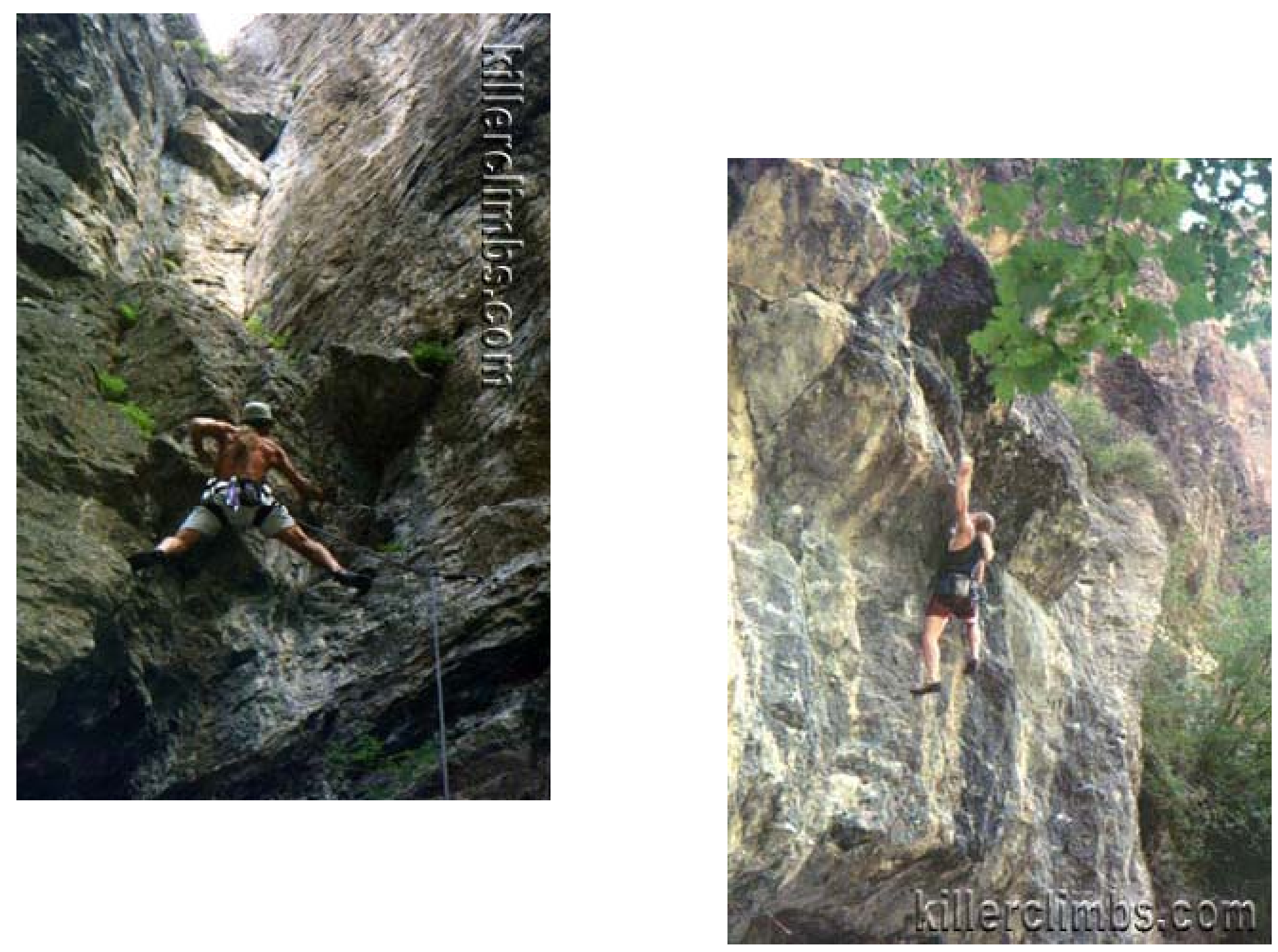


\section{History of Ergonomics at JGI (Dec 2005-Current)}

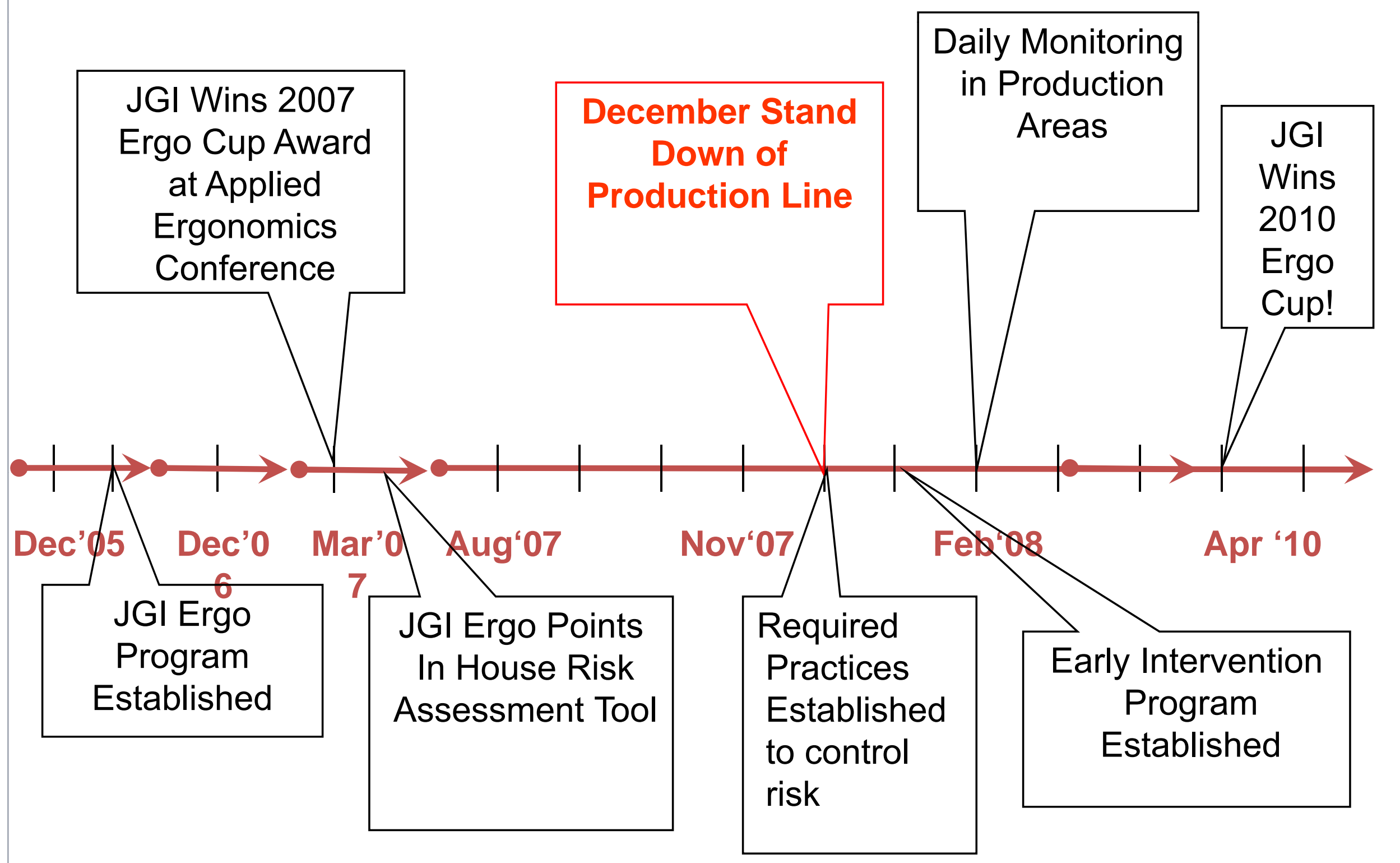




\section{Recordable Injury History}

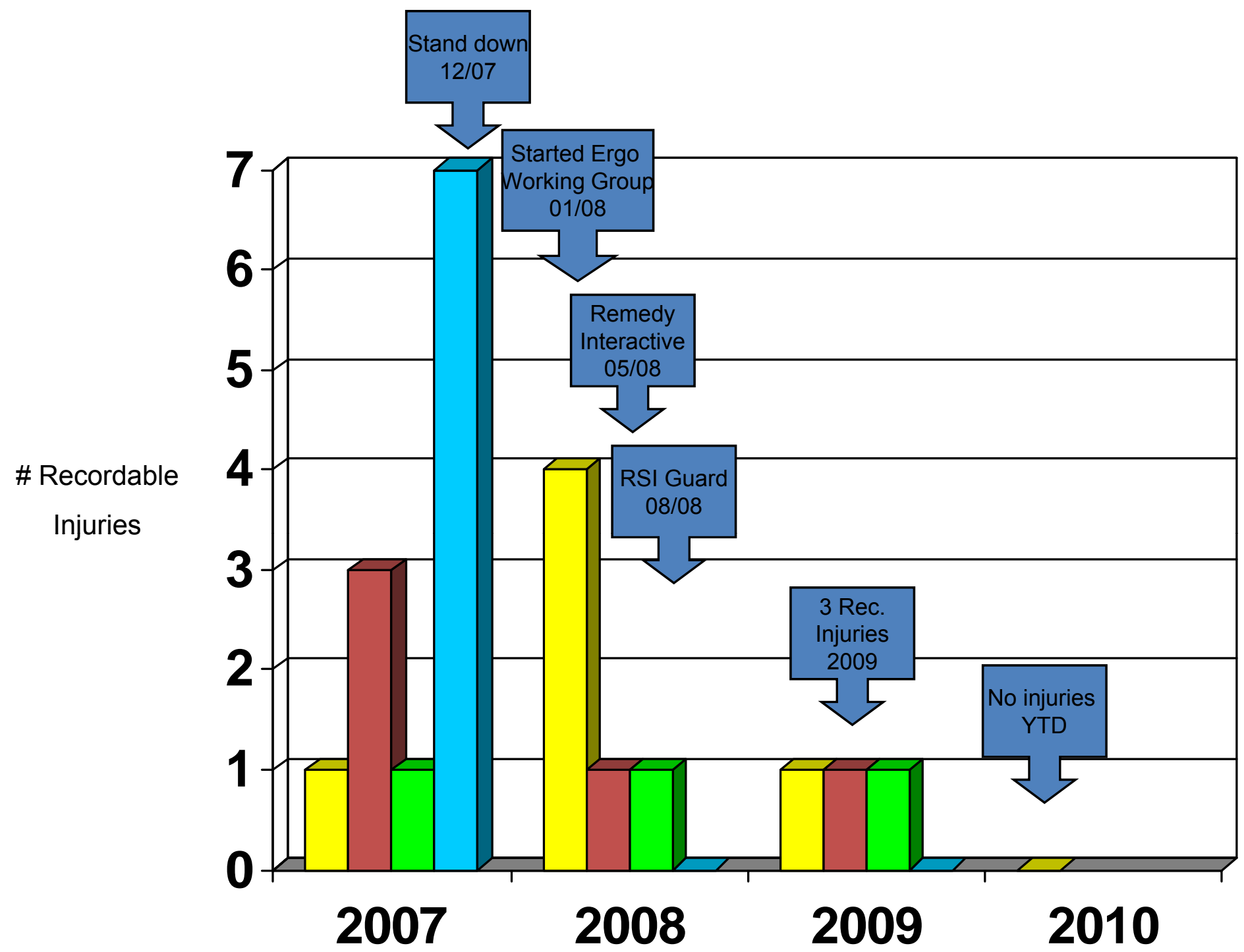

$\square$ Q1
$\square$ Q2
$\square$ Q3
$\square$ Q4 


\section{Engineering designs and solutions}

\section{Early intervention}

\section{Targets employees \\ with discomfort \\ Includes bi-weekly \\ review meeting}

Proactive Efforts

Labs and offices Monitoring

Walk-abouts

Comfort surveys

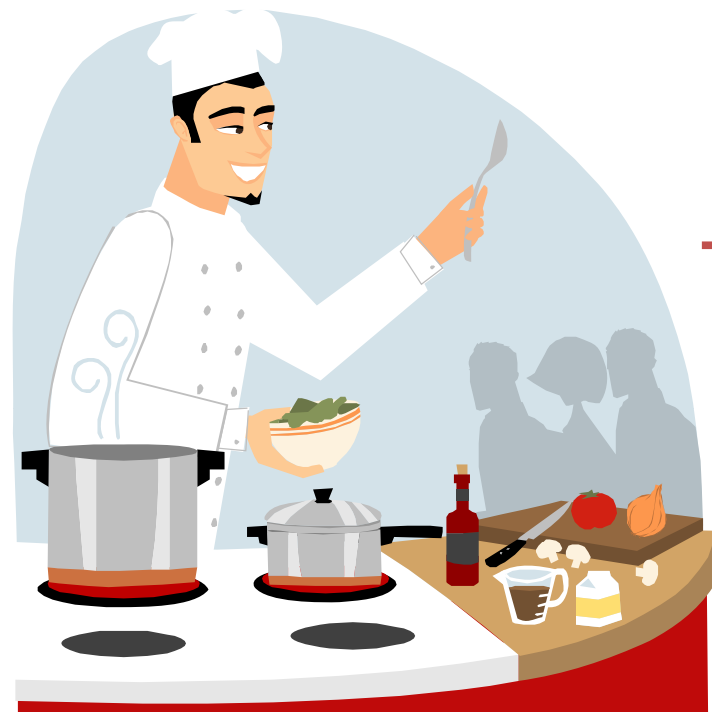

Relaxation/Rejuvenation Room
Safety Culture Working Group

Promotion

Awareness

Communication
Training/education

Risk targeted classes

Stretch break programs

Potty training

Website resources

Ergonomics Demo Room

Work tool and practices

Ergo Points

Required Practices 


\section{J 5 Top 3 High Risk Factor Tasks (Pre-2007)}

Thermal Cycler Loading $\quad$ Peeling Seals
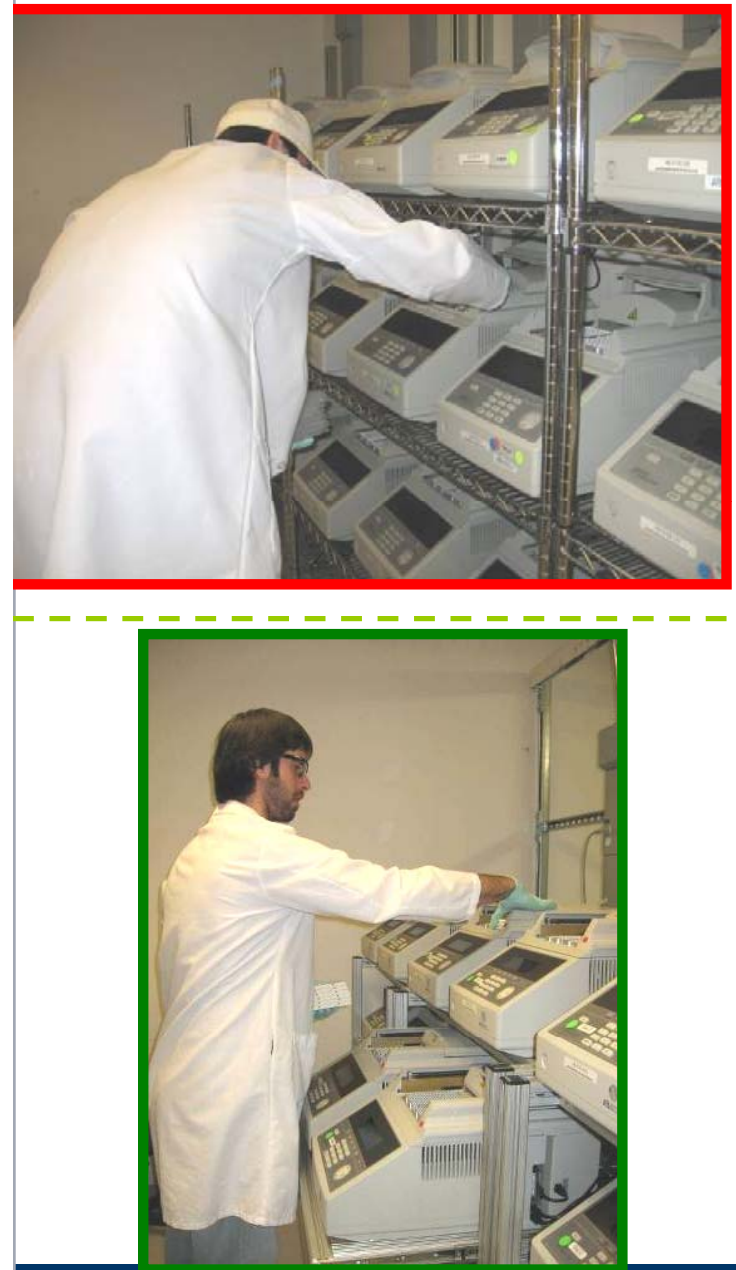
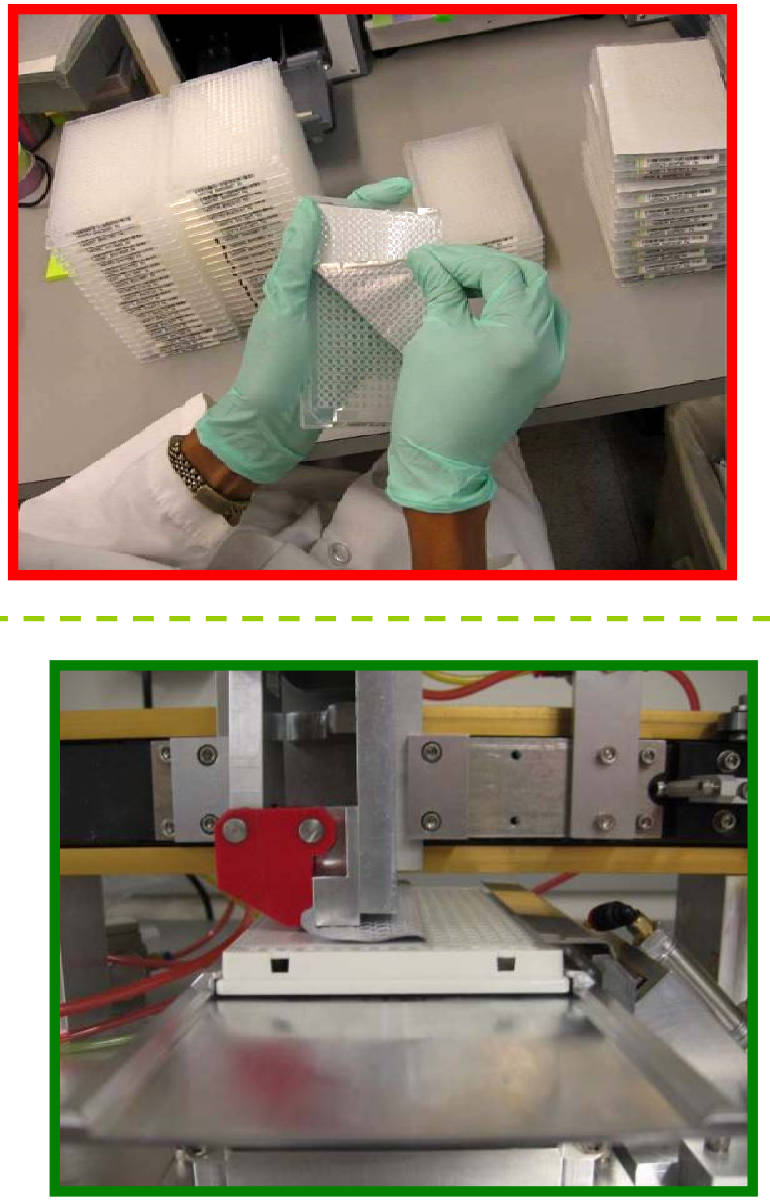

Freezer Rack Lifting
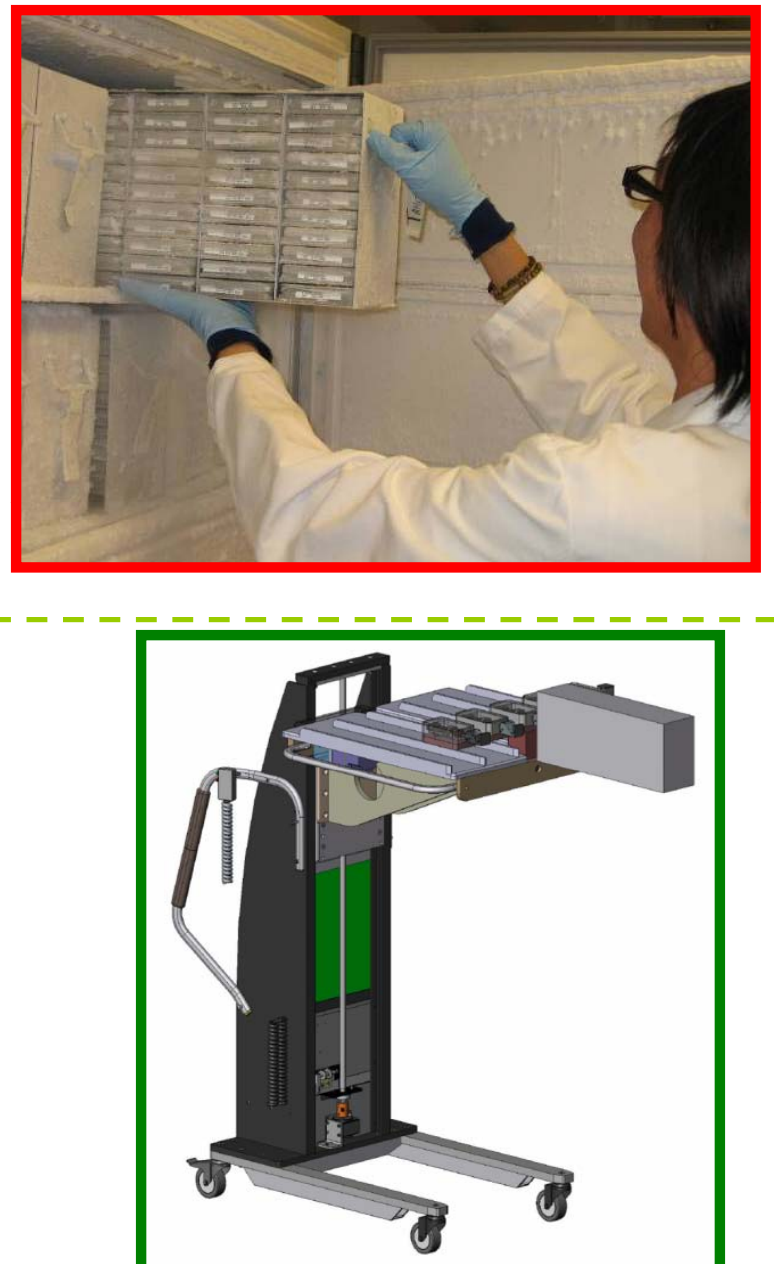


\section{J 5 Top 3 High Risk Factor Tasks (Now-2010)}

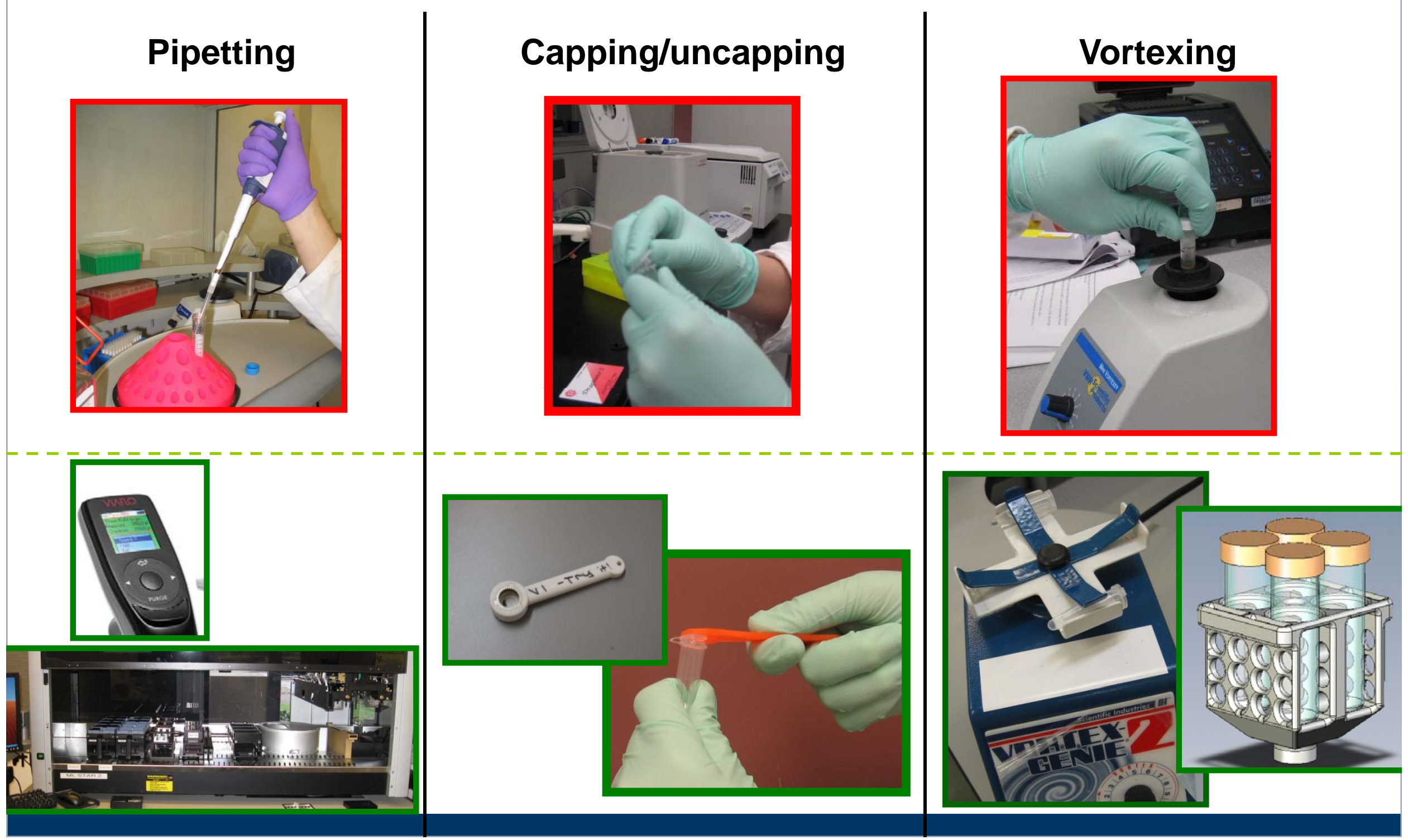



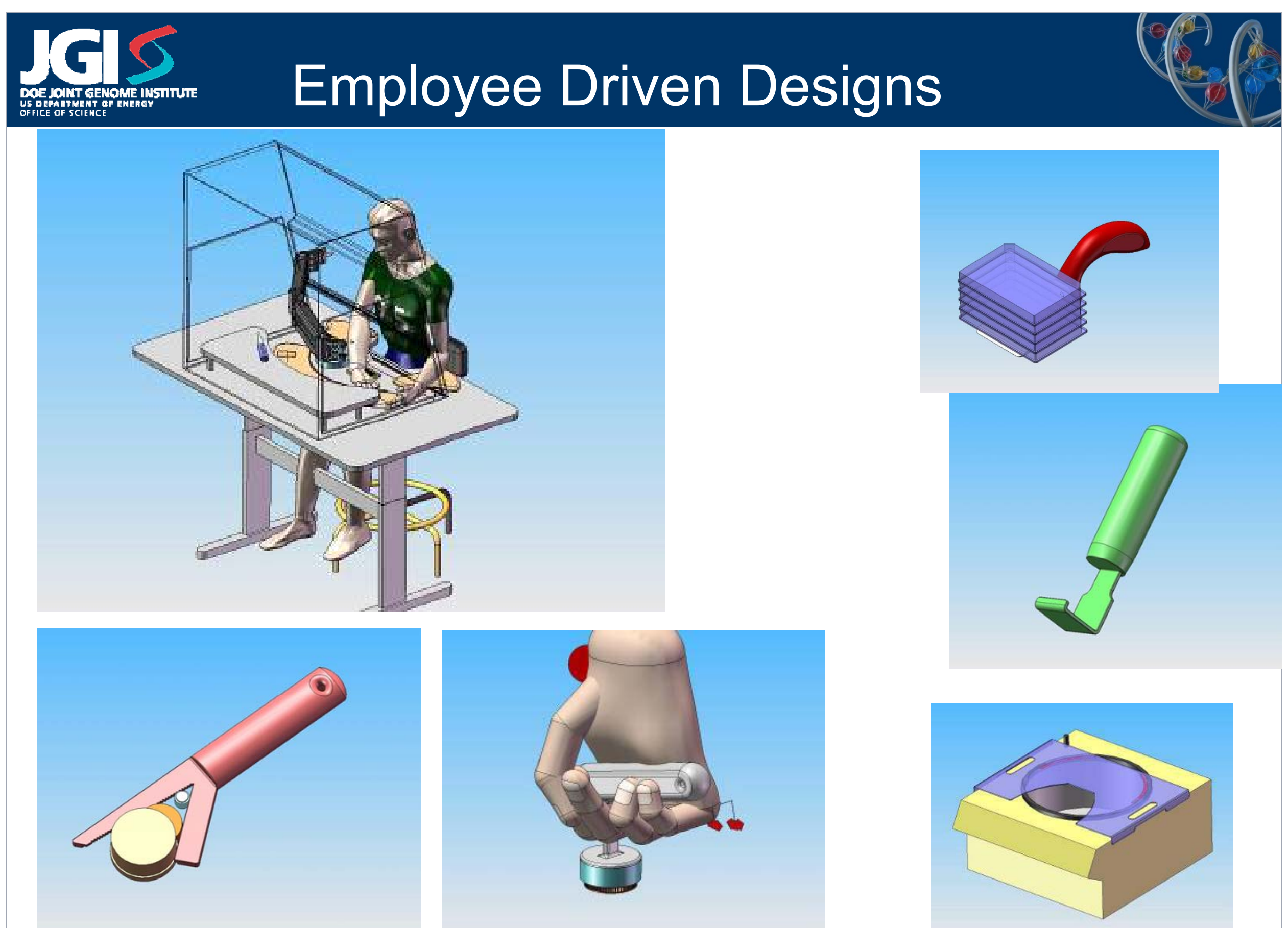


\section{]C] Best Practices= Do's and Don'ts}
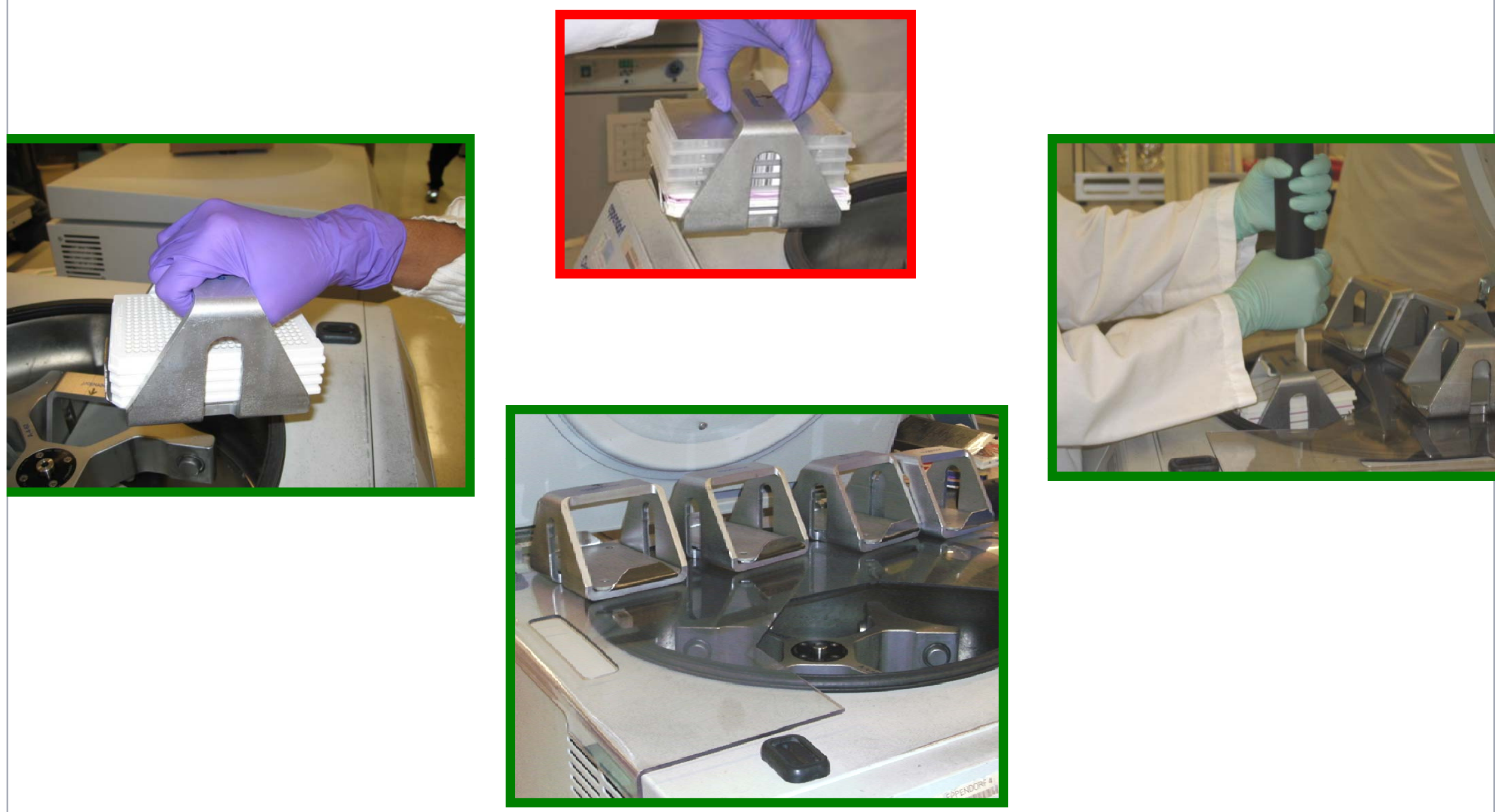


\section{JGI Wins the Ergo Cup Again!}

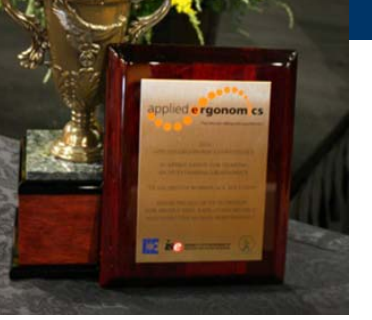

FOR...the Ergonomic Program Improvement Initiatives category: “Empowering Employees in Ergonomics," which focused on the employee-driven elements of the JGI Ergonomics Program.

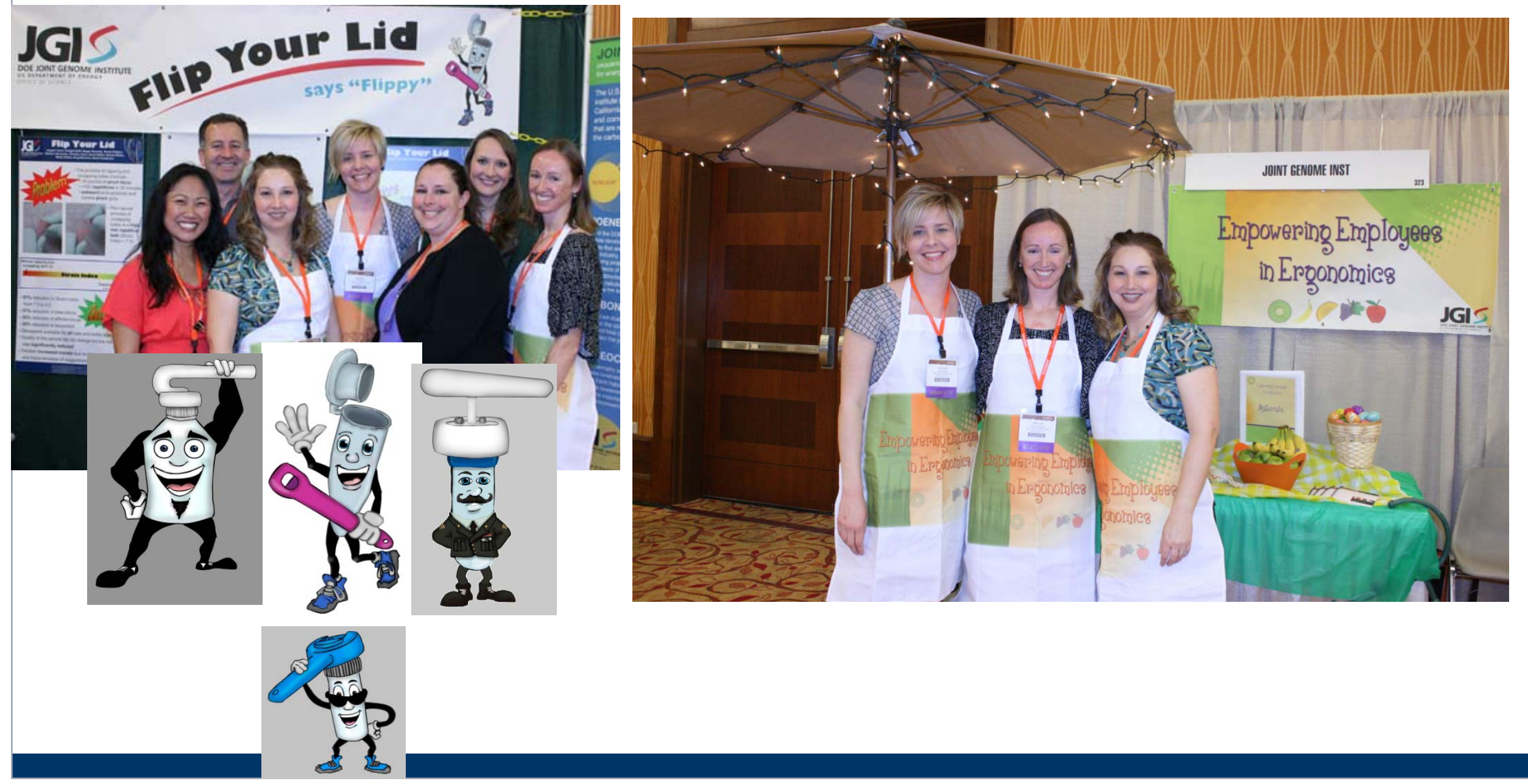


- Healthy to have discussions about readiness and obstacles

- Have plans to address obstacles

- Involve 'nay sayers'

- Sell, sell, and sell some more

- Communicate

- Advertise

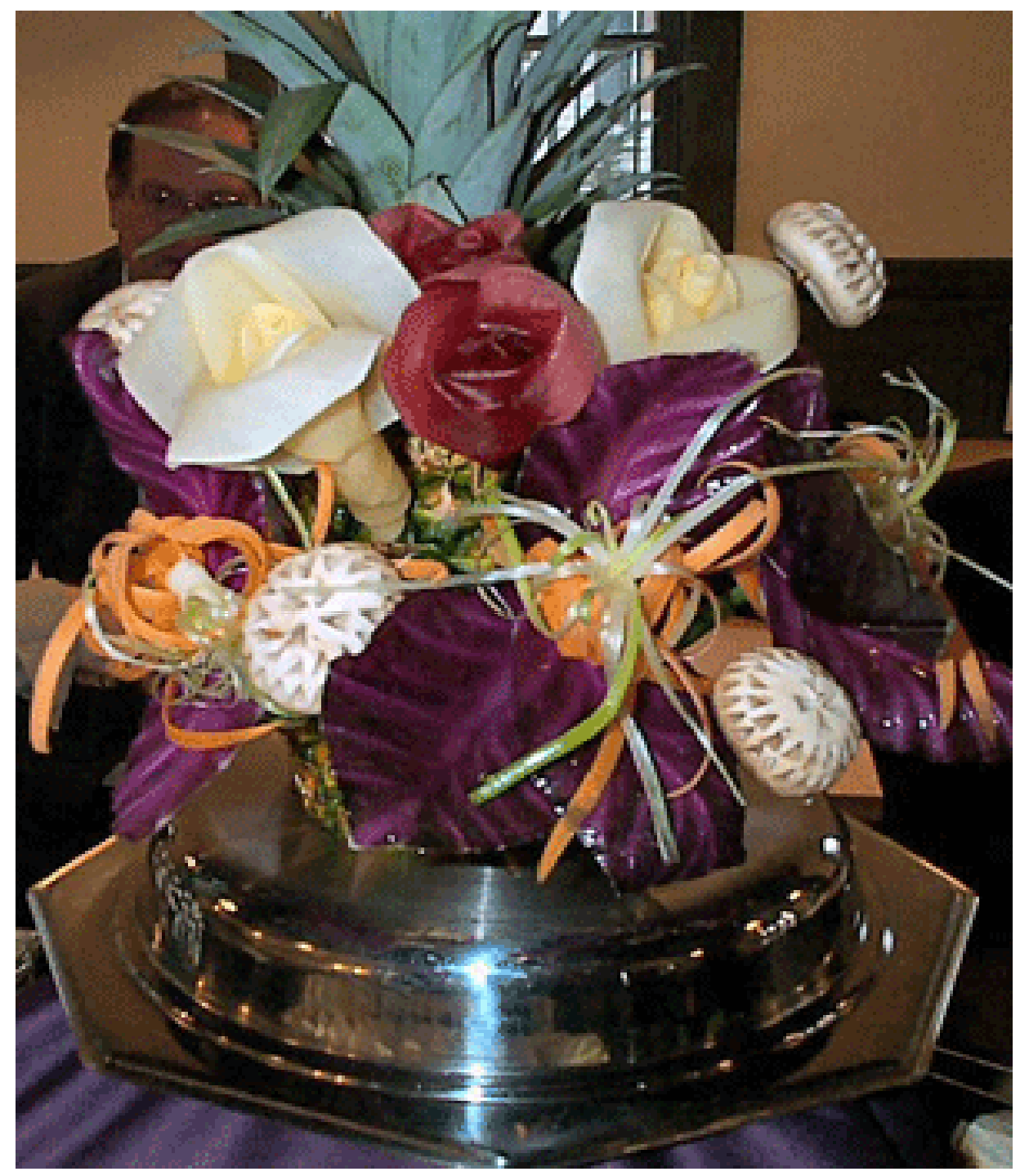


IF

If you think an ergonomics program may be ready to start, change, or improve....
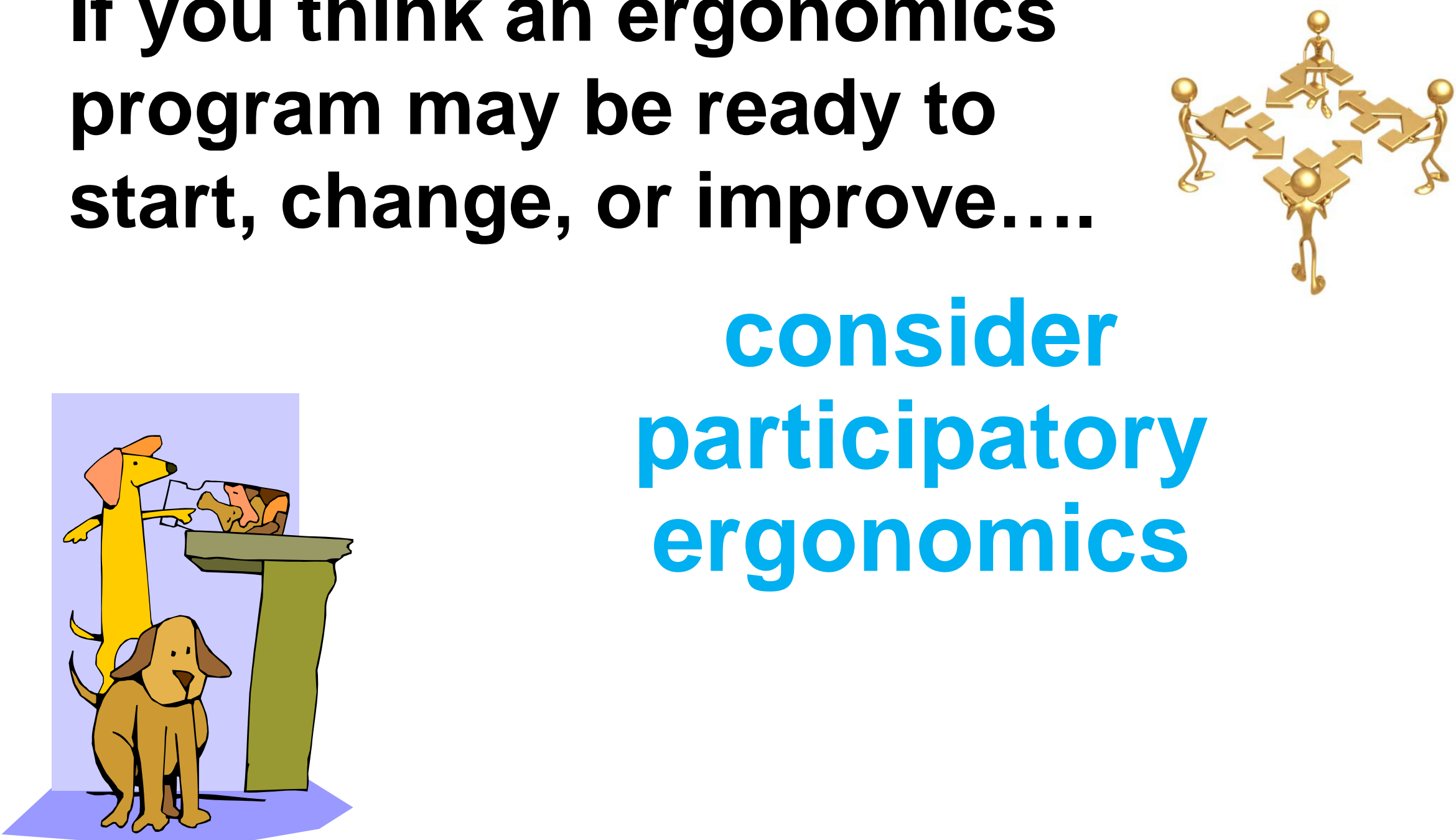

consider

participatory ergonomics 


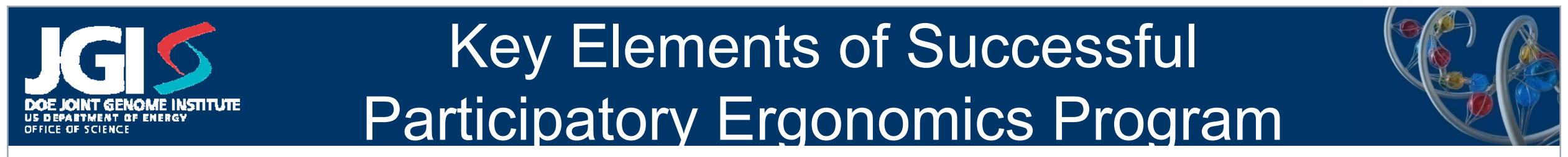

- Employee involvement

- Getting the employees involved to identify problems and suggest solutions

- Management commitment

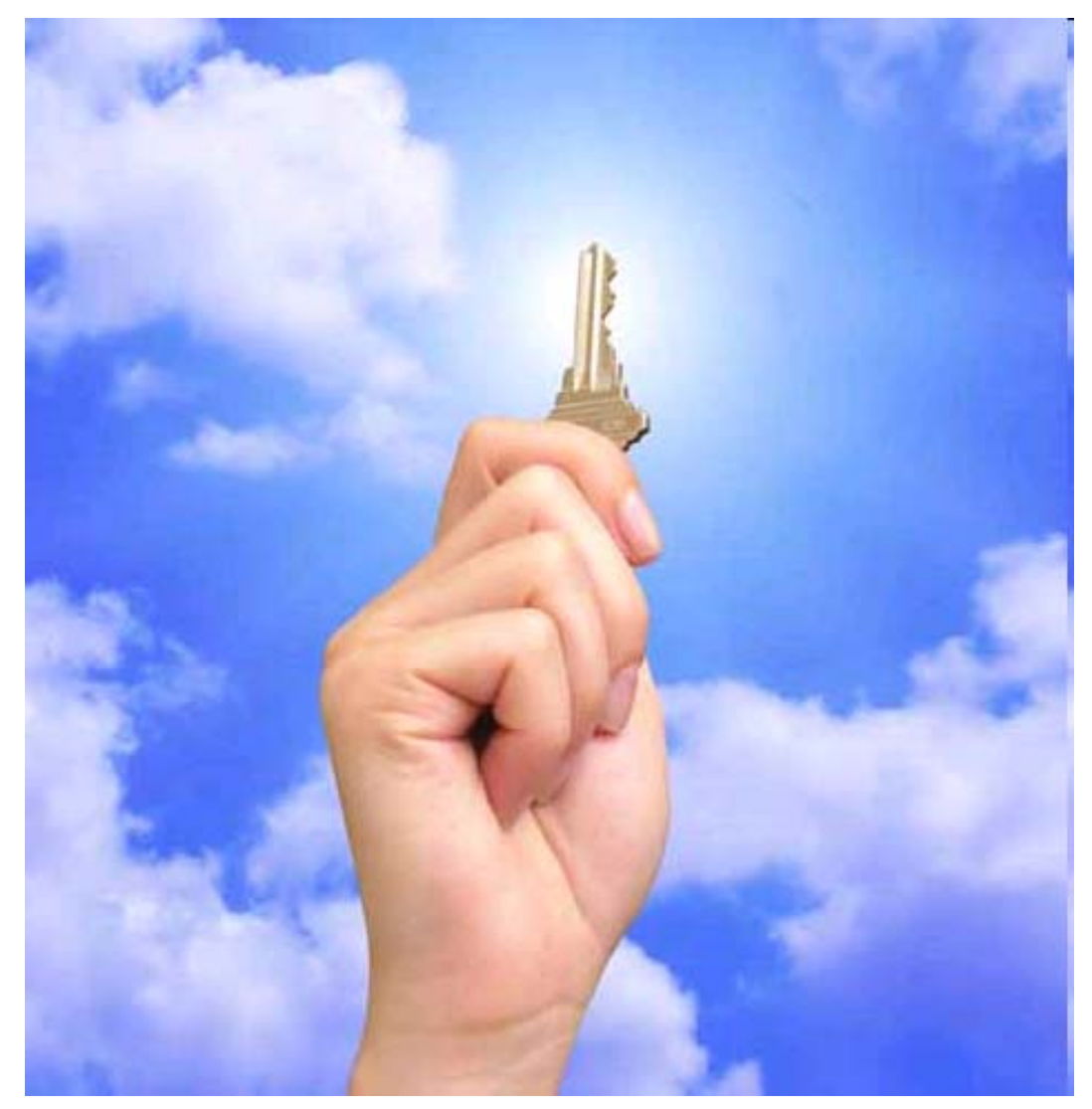


JC 5 Key Elements of Successful Participatory Ergonomics Program (continued)

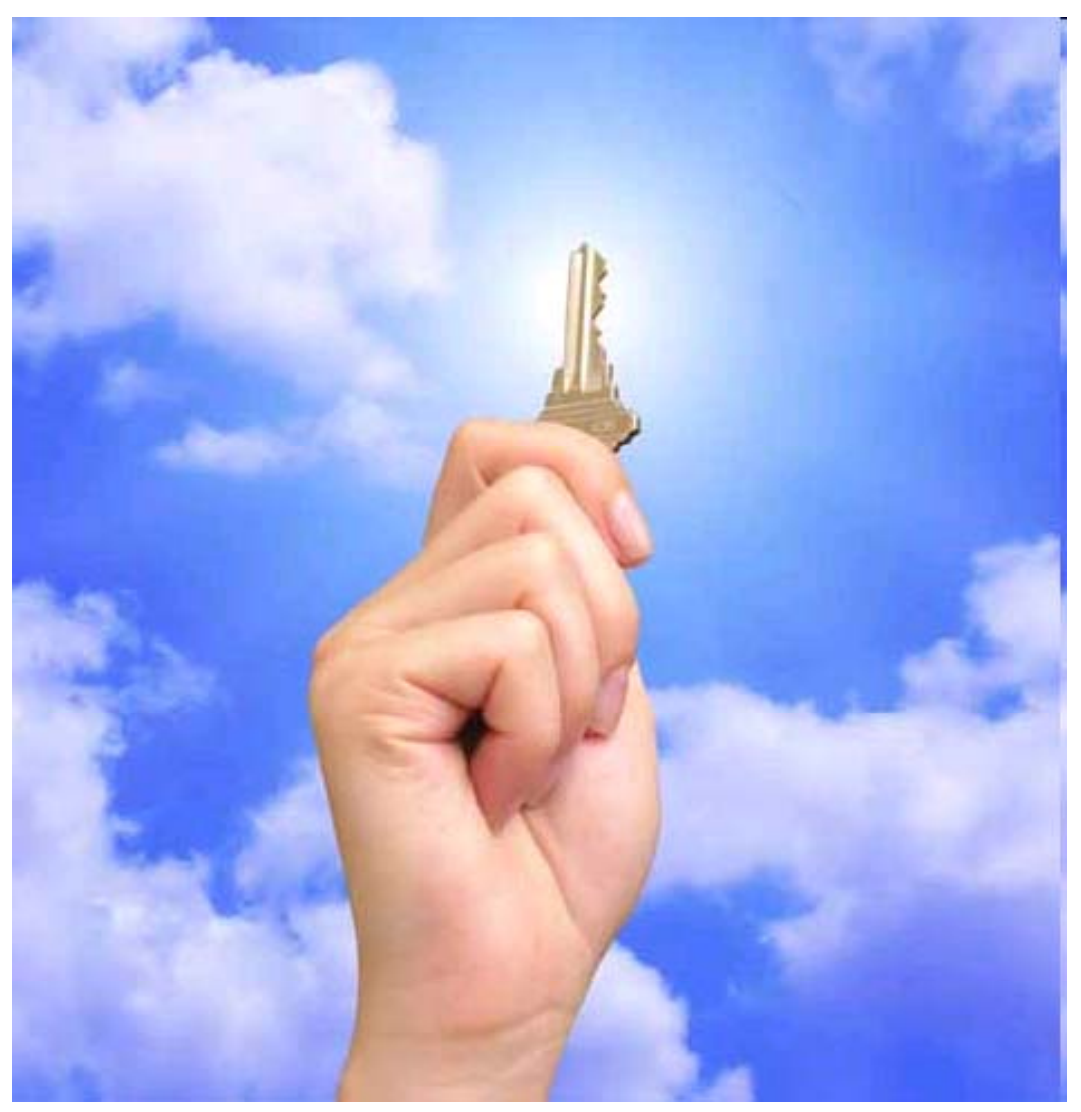

- Establish defined processes and roles

- Allow for flexibility in doing tasks (one size does not fit all)

- Align with existing programs/ efforts 


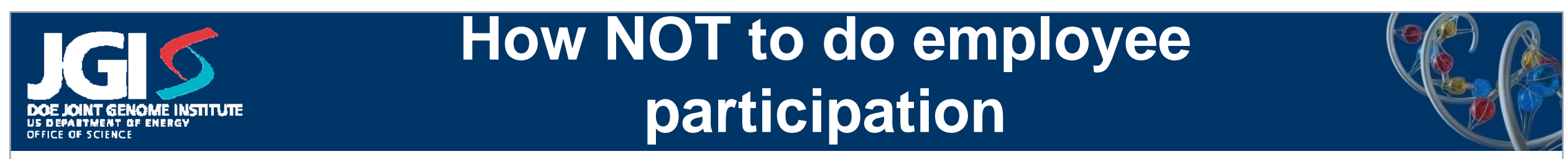

(c) 1999 Randy Glasbergen.

www.glasbergen.com

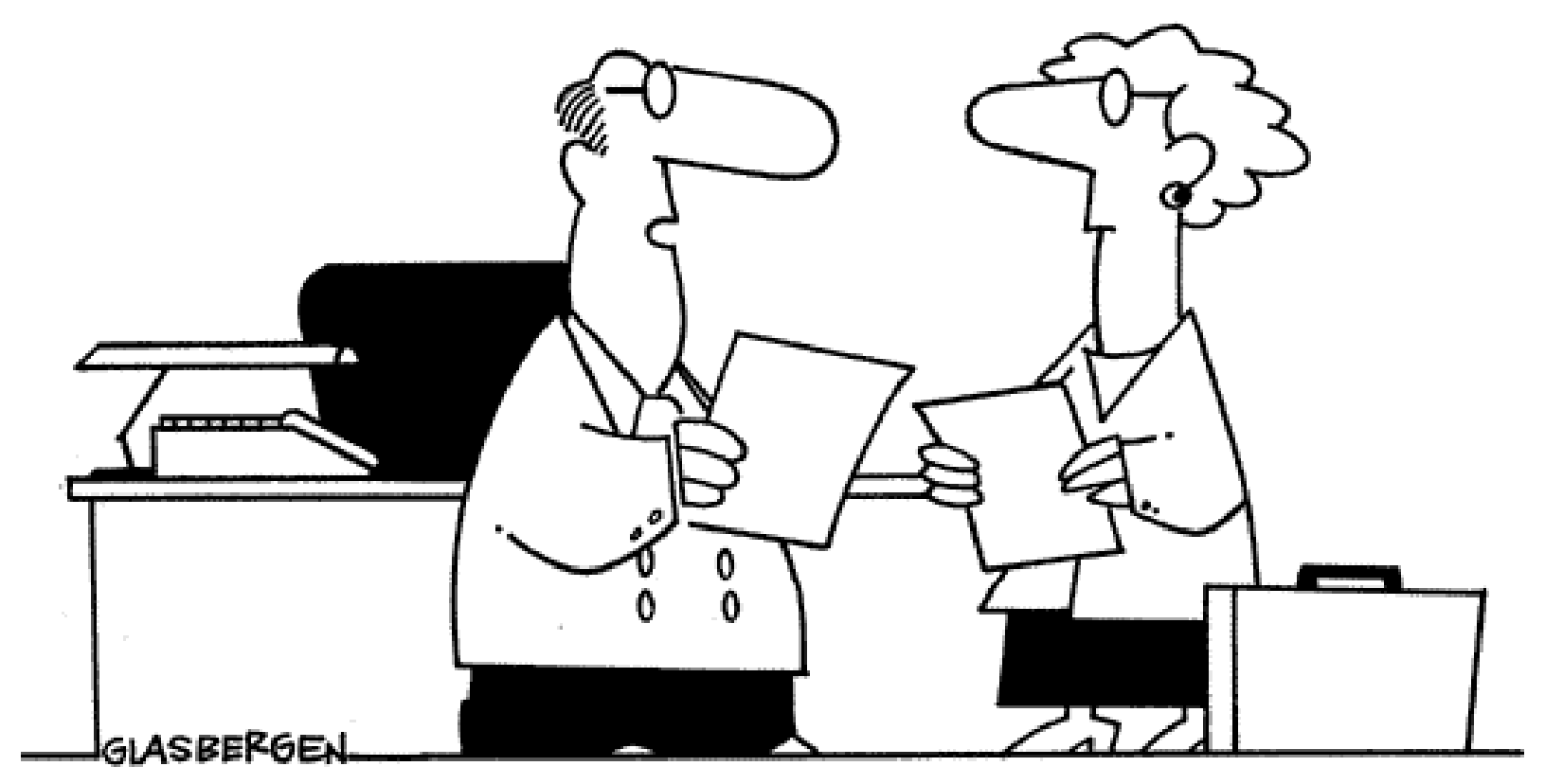

"Let's form a committee to create a task force to develop a team to determine the fastest way to deal with the problem." 


\section{Benefits of implementation}

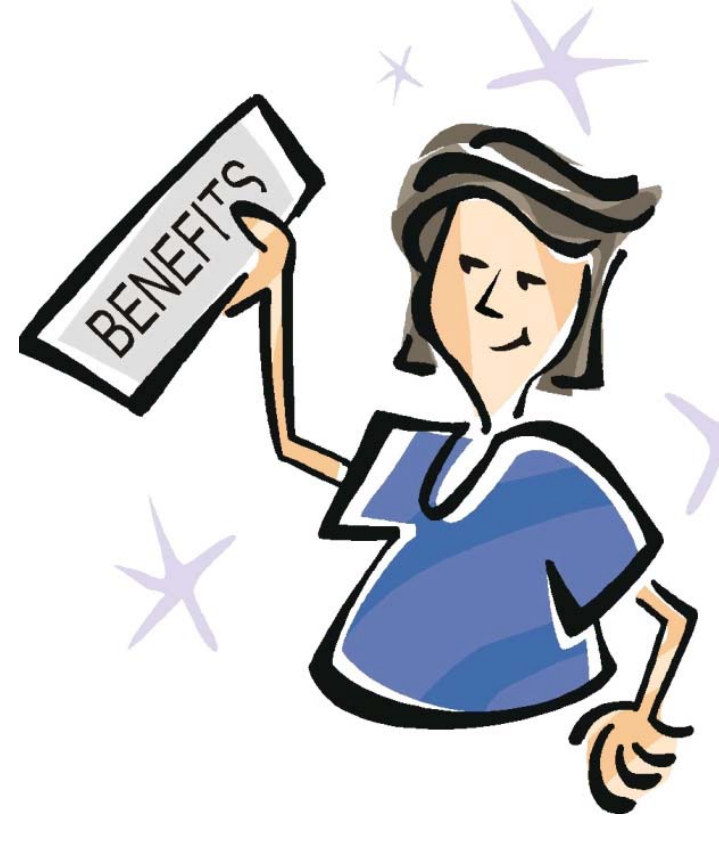

- Increased productivity

- Improved quality of work

- Improvement in employee morale

- Cost savings both in possible reduction in injury-related and production costs

- Time savings 


\section{Challenges of implementation}

- Risk of short term increase of injuries

- Buy-in from management

- Up front costs associated with training and education

- Time

- Requires risk

- Change, and the uncertainty of change

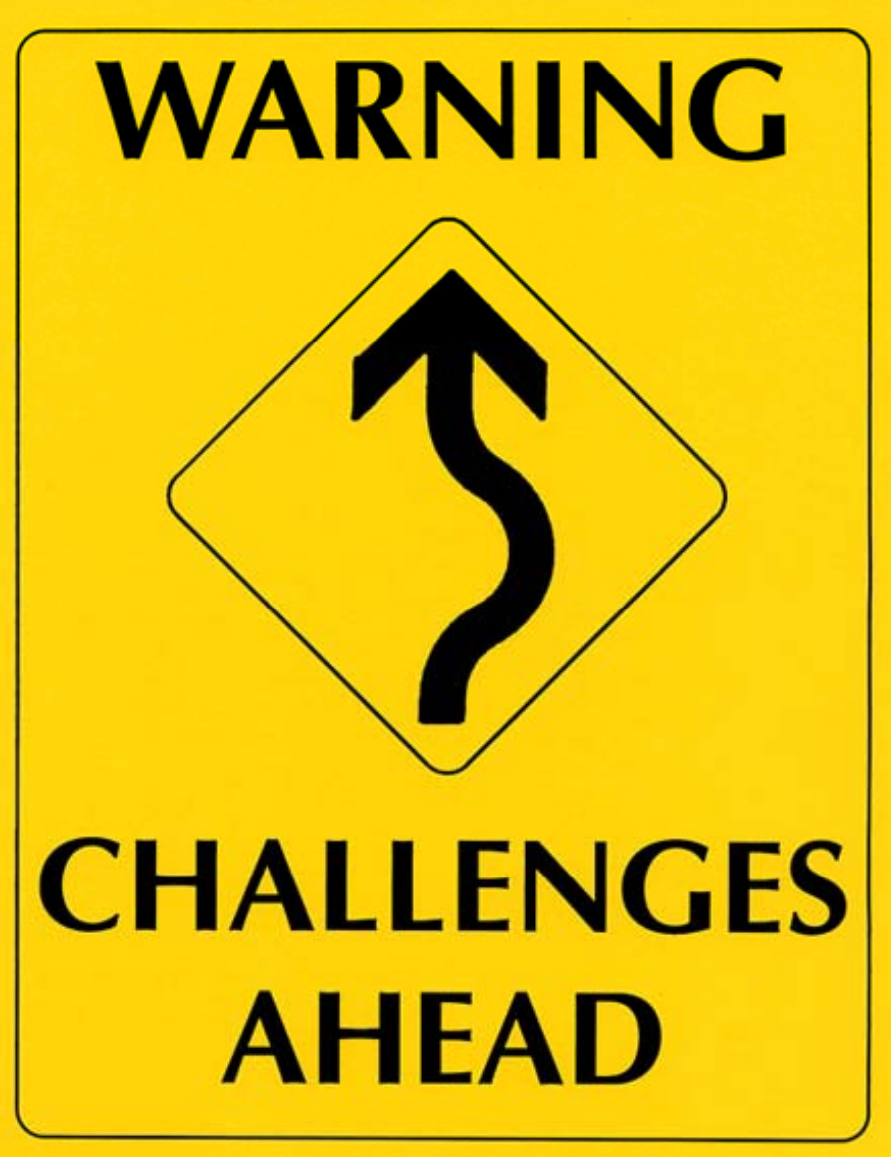




\section{A moment about change...}

People don't resist change...they resist being changed!

Copyright 2002 by Randy Glasbergen.

www.glasbergen.com

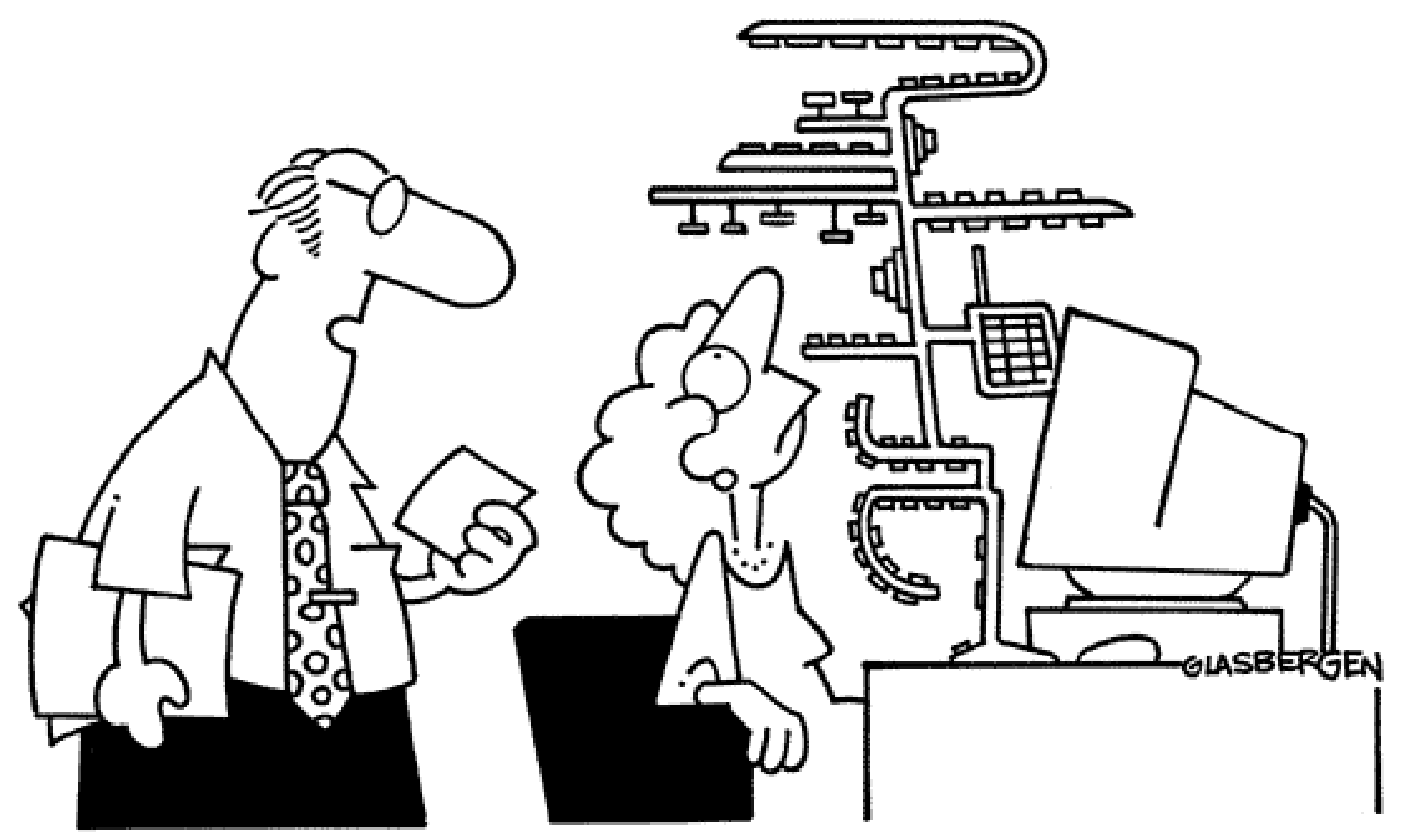

"It's an ergonomic keyboard. Once you learn how to use it, it will increase your speed by six percent!" 


\section{How to get started?}

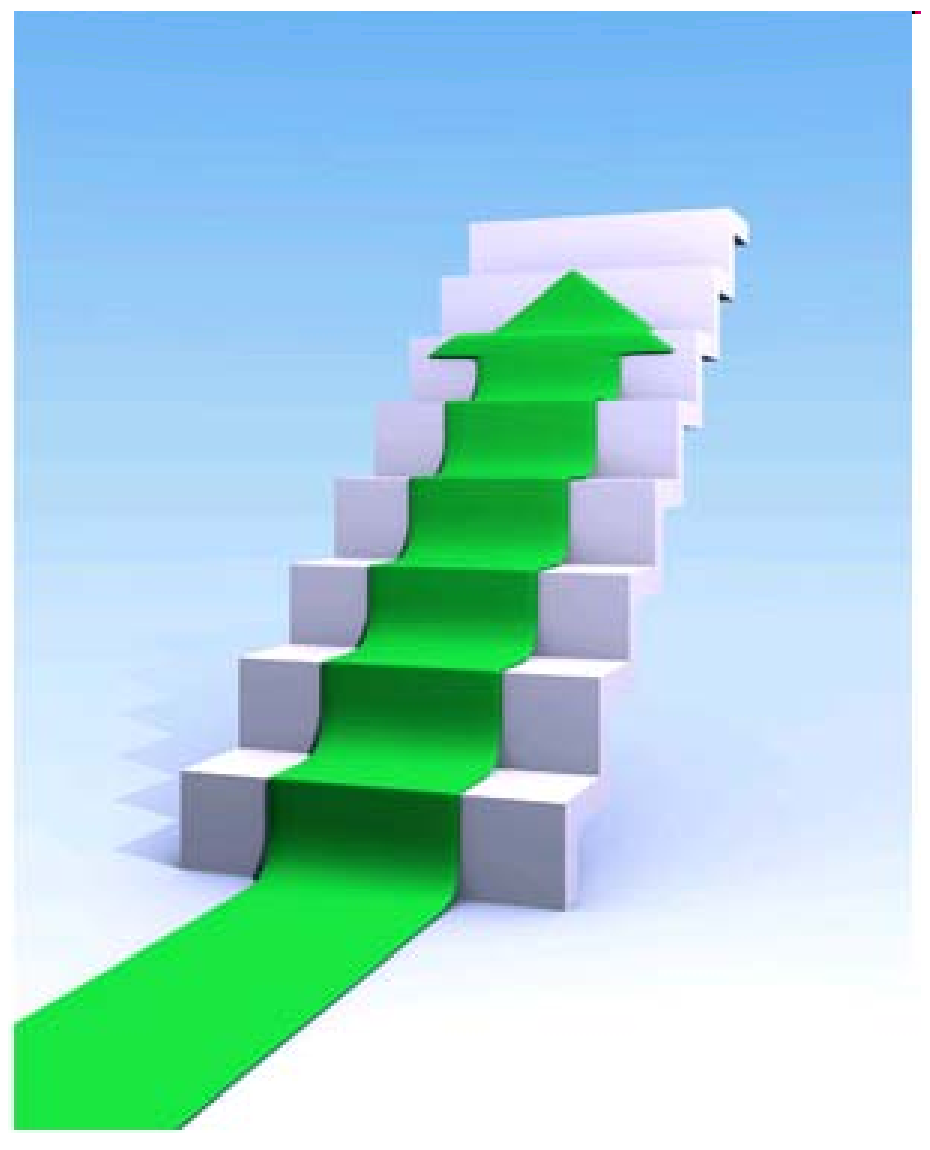

- Assess where you are currently

- Determine who should be trained and train them on how to identify risks, preventions and control methods.

- Involve employees

- Identify problem areas

- Develop and try solutions

- Clearly define roles and responsibilities

- Determine priorities for change

- Do you have managements buy-in and commitment? 
Lack of commitment will be very obvious to employees

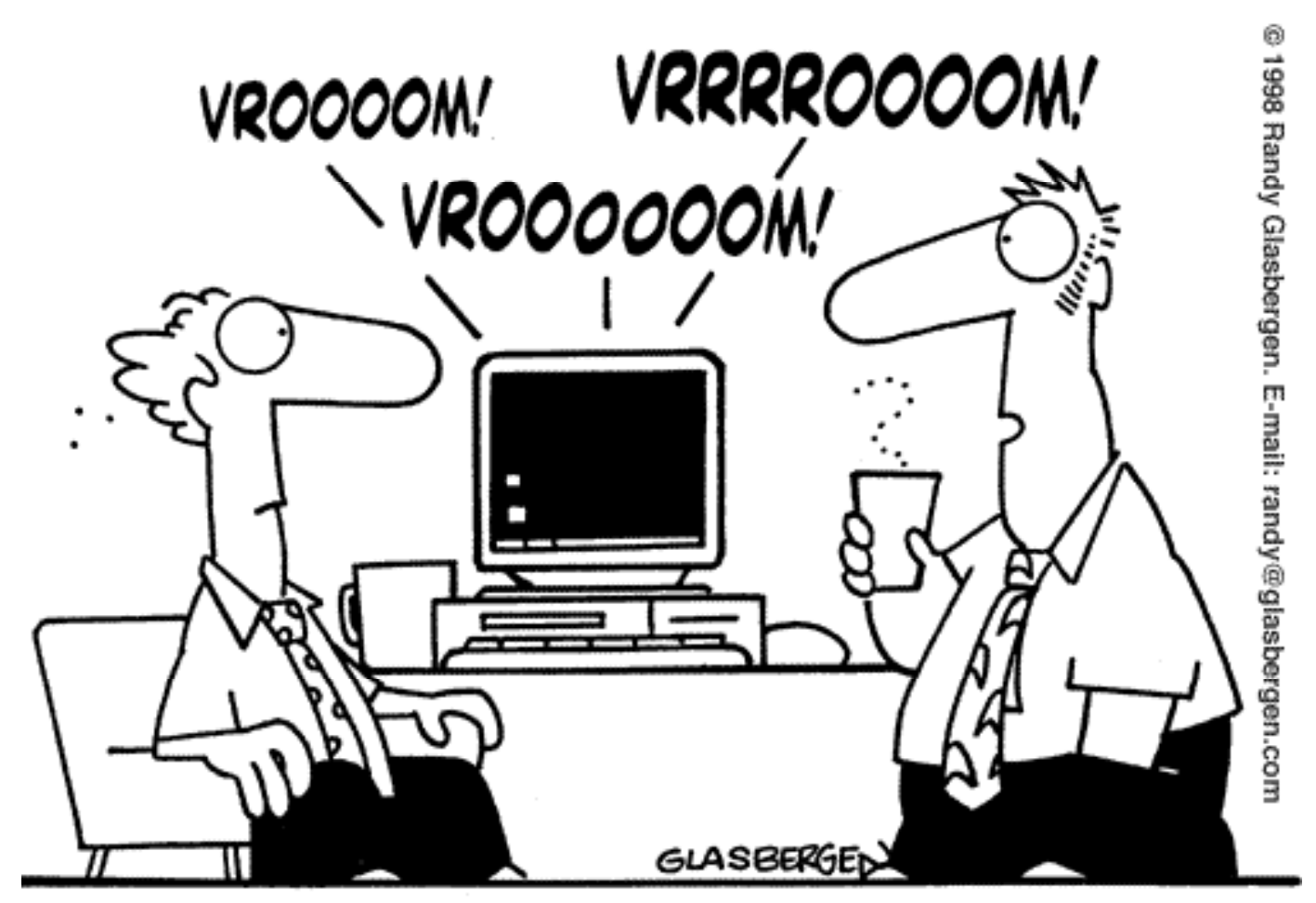

"We couldn't afford faster computers, so we just made them sound faster." 


Employees and supervisors
should have basic knowledge

- Ergonomic-related risk factors and symptoms

- Ways to identify and assess hazards specific to job tasks

- Safe use of tools, equipment and materials

- Understanding of safe work practices and processes

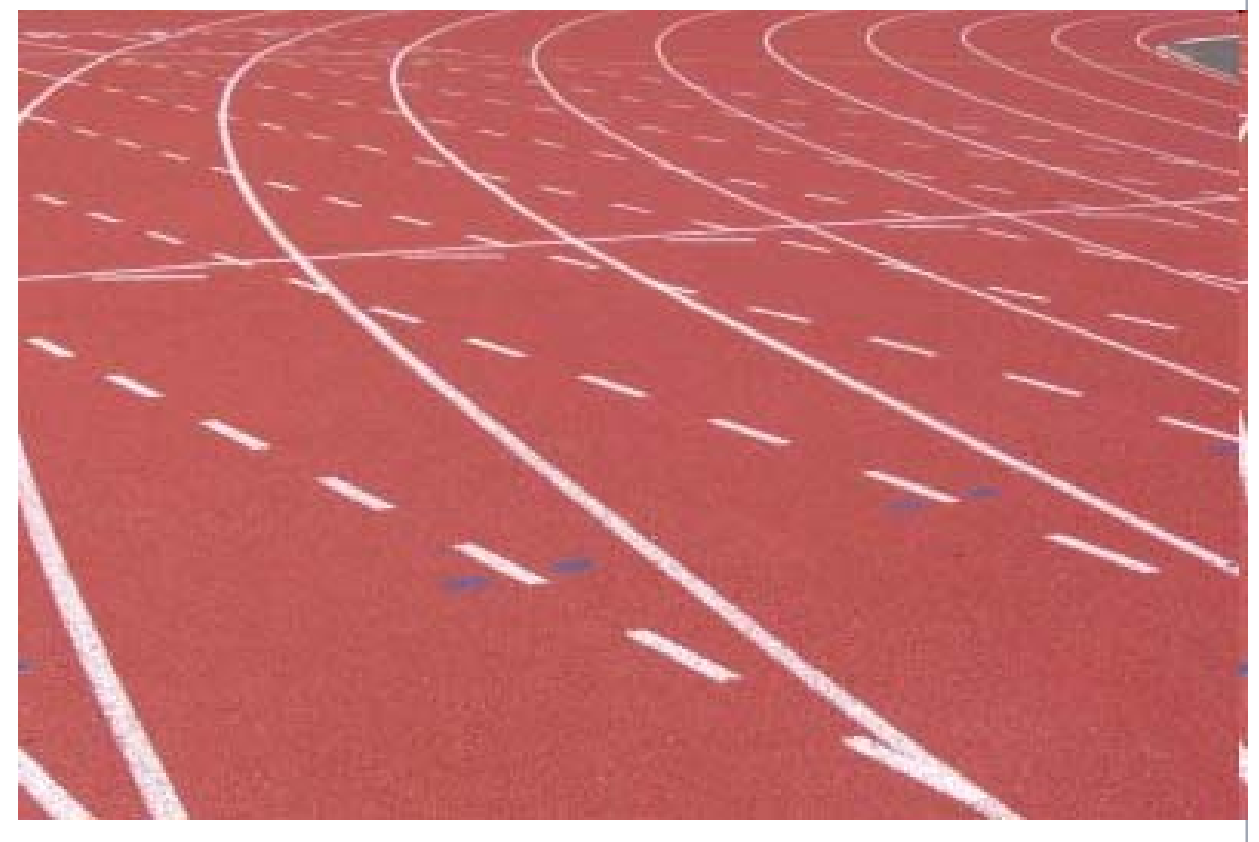

- Mechanisms for reporting concerns or ideas 


\section{JC Is there any proof participatory}

eroonomics works?

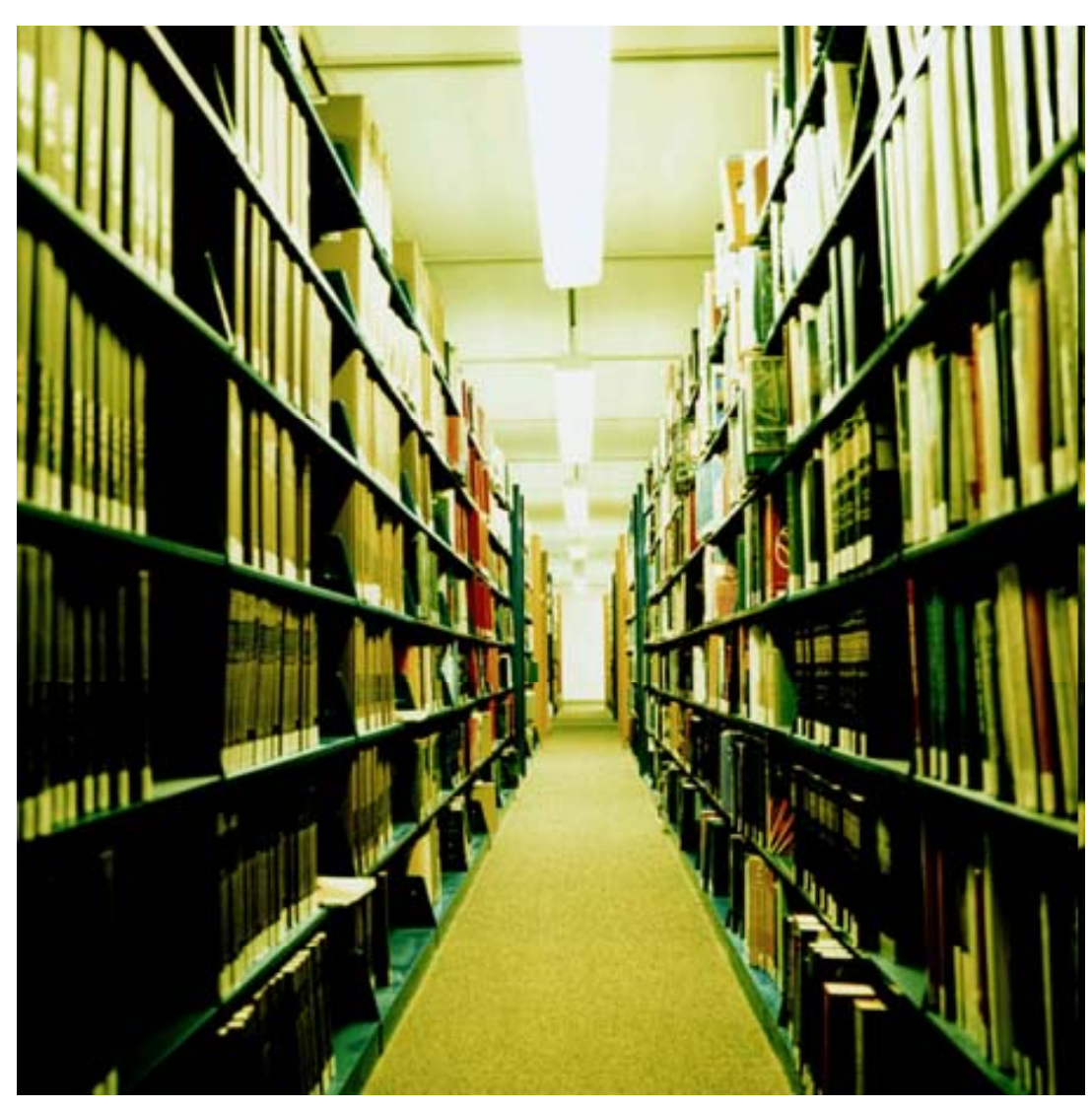

What does the research say?

Reduction in injuries and workers compensation costs

Employees with back pain involvement in establishing iob modifications

Resources/ References: Occupational Health \& Safety Agency for Healthcare in British Columbia 


\section{Jes}

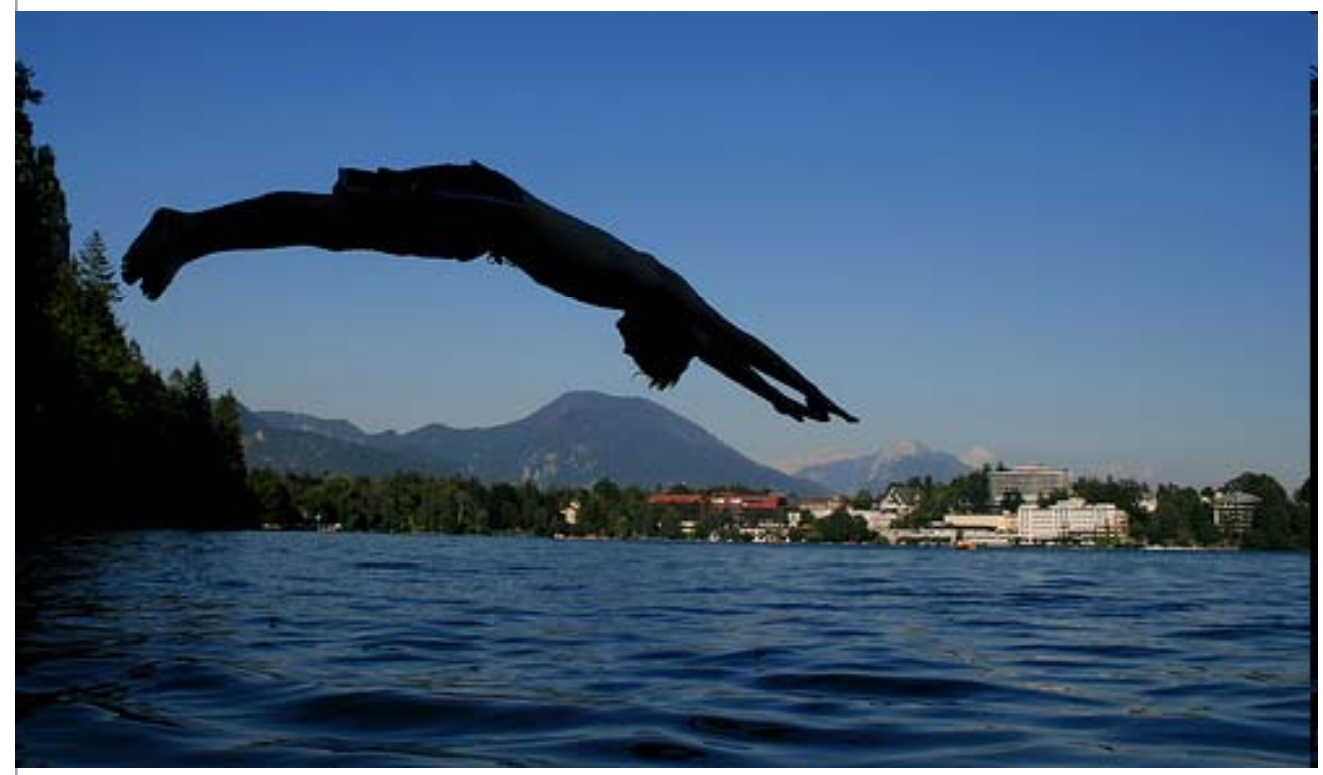

$$
\text { Thanlk youl }
$$

Melanie Alexandre

mmalexandre@llbl.gov

$$
925-927-2553
$$

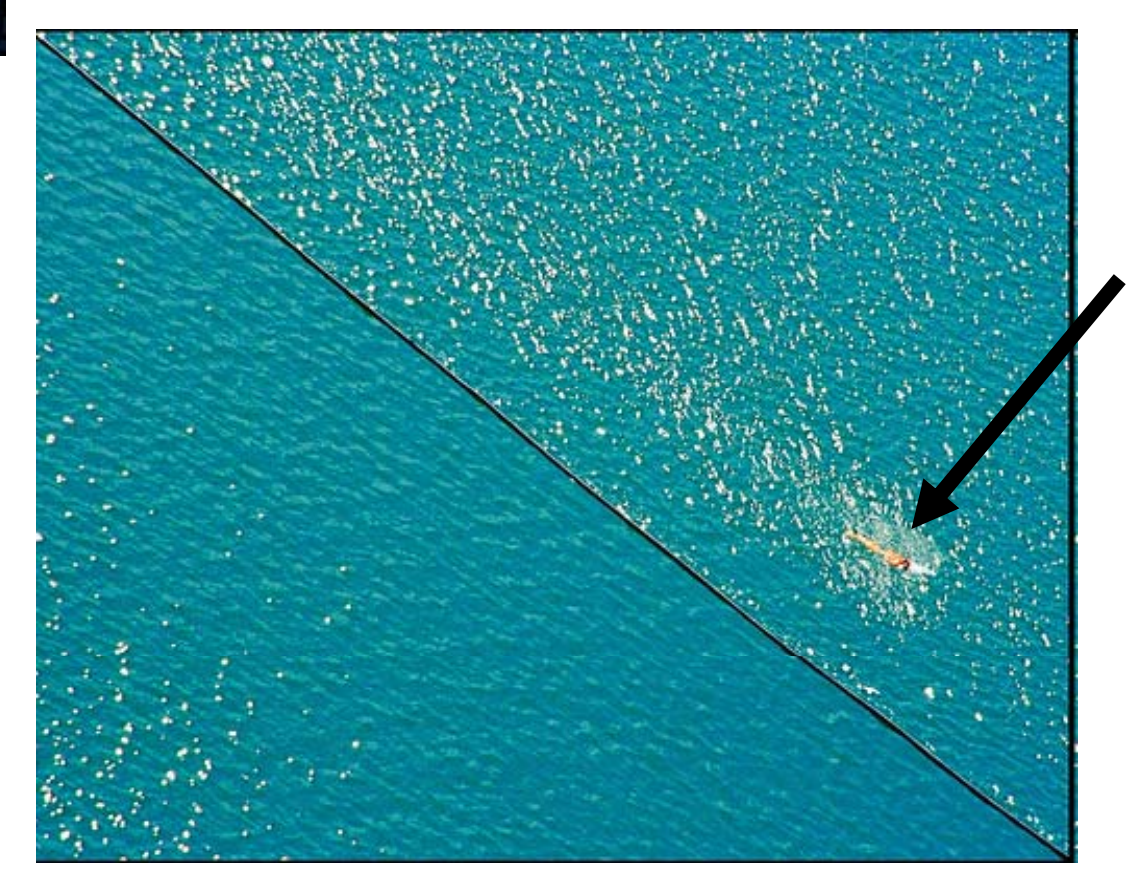

